\title{
Human placental trophoblast invasion and differentiation: a particular focus on Wnt signaling
}

\section{Martin Knöfler* and Jürgen Pollheimer}

Department of Obstetrics and Fetal-Maternal Medicine, Reproductive Biology Unit, Medical University of Vienna, Austria

\section{Edited by:}

Marie Van Dijk, VU University Medical

Center, Netherlands

\section{Reviewed by:}

Sascha Drewlo, Wayne State University School of Medicine, USA

Nardhy Gomez-Lopez, Wayne State University, USA

\section{*Correspondence:}

Martin Knöfler, Department of Obstetrics and Fetal-Maternal

Medicine, Reproductive Biology Unit, Medical University of Vienna,

Waehringer Guertel 18-20, A-1090

Vienna, Austria

e-mail:martin.knoefler@

meduniwien.ac.at
Wingless ligands, a family of secreted proteins, are critically involved in organ development and tissue homeostasis by ensuring balanced rates of stem cell proliferation, cell death and differentiation. Wnt signaling components also play crucial roles in murine placental development controlling trophoblast lineage determination, chorioallantoic fusion and placental branching morphogenesis. However, the role of the pathway in human placentation, trophoblast development and differentiation is only partly understood. Here, we summarize our present knowledge about Wnt signaling in the human placenta and discuss its potential role in physiological and aberrant trophoblast invasion, gestational diseases and choriocarcinoma formation. Differentiation of proliferative first trimester cytotrophoblasts into invasive extravillous trophoblasts is associated with nuclear recruitment of $\beta$-catenin and induction of Wnt-dependent T-cell factor 4 suggesting that canonical Wnt signaling could be important for the formation and function of extravillous trophoblasts. Indeed, activation of the pathway was shown to promote trophoblast invasion in different in vitro trophoblast model systems as well as trophoblast cell fusion. Methylation-mediated silencing of inhibitors of Wnt signaling provided evidence for epigenetic activation of the pathway in placental tissues and choriocarcinoma cells. Similarly, abundant nuclear expression of $\beta$-catenin in invasive trophoblasts of complete hydatidiform moles suggested a role for hyper-activated Wnt signaling. In contrast, upregulation of Wnt inhibitors was noticed in placentae of women with preeclampsia, a disease characterized by shallow trophoblast invasion and incomplete spiral artery remodeling. Moreover, changes in Wnt signaling have been observed upon cytomegalovirus infection and in recurrent abortions. In summary, the current literature suggests a critical role of Wnt signaling in physiological and abnormal trophoblast function.

Keywords: placenta, human, trophoblast, invasion, Wnt

\section{DEVELOPMENT AND FUNCTION OF THE HUMAN PLACENTA}

Development of the human placenta is critical for embryonic development and successful pregnancy outcome. Immediately after implantation, trophectodermal cells forming the outermost epithelial layer of the blastocyst give rise to diverse trophoblast cell types (Hamilton and Boyd, 1960; Cross et al., 1994). Cell fusion generates the primitive syncytium underneath the implanted embryo, which may represent the earliest invasive trophoblast cell type migrating into the maternal endometrium (Figure 1A). After formation of the lacuna system, the ancestor of the intervillous space, cytotrophoblasts (CTBs) emanating from the trophectodermal layer generate primary villi by proliferation and invasion through the primitive syncytium (Figure 1B). Throughout pregnancy, these primary villi transform into secondary and tertiary villi characterized by invasion of extraembryonic mesenchymal cells, villous branching, and vascularization. During the first trimester of pregnancy two types of mature villi can be discriminated, which are floating and anchoring villi (Figure 1C). Floating villi connected to the intervillous space represent the transport units of human placenta. After establishment of blood flow nutrients and oxygen pass the epithelial layers of these villi ensuring appropriate fetal development and growth. Multinucleated syncytiotrophoblasts covering the surface of floating villi are continuously generated by asymmetrical cell division, differentiation and fusion of villous cytotrophoblasts (vCTBs) with the developing syncytium (Aplin, 2010). The latter also secretes numerous hormones, such as human chorionic gonadotrophin, into the maternal circulation, which are required for maintenance and immunological adaptation of pregnancy (Bansal et al., 2012). Fusion process and numbers of vCTBs decrease during pregnancy. Hence at term, syncytiotrophoblasts are in close contact with placental vessels allowing efficient nutrient uptake by the fetus.

Villi connected to the basal plate of the human placenta give rise to proliferative cell columns from which differentiated extravillous trophoblast (EVT) cell types are generated. At early stages of pregnancy, invasive endovascular cytotrophoblasts (eCTBs) plug the maternal arterioles to prevent premature onset of blood flow into the intervillous space (Pijnenborg et al., 2006). Failures in this process were shown to be associated with pregnancy complications such as abortions likely due to the premature rise in oxygen levels which may provoke oxidative stress and damage of placental villi (Hustin et al., 1990; Burton et al., 2010). Besides endovascular invasion, interstitial cytotrophoblasts (iCTBs) migrate into the 

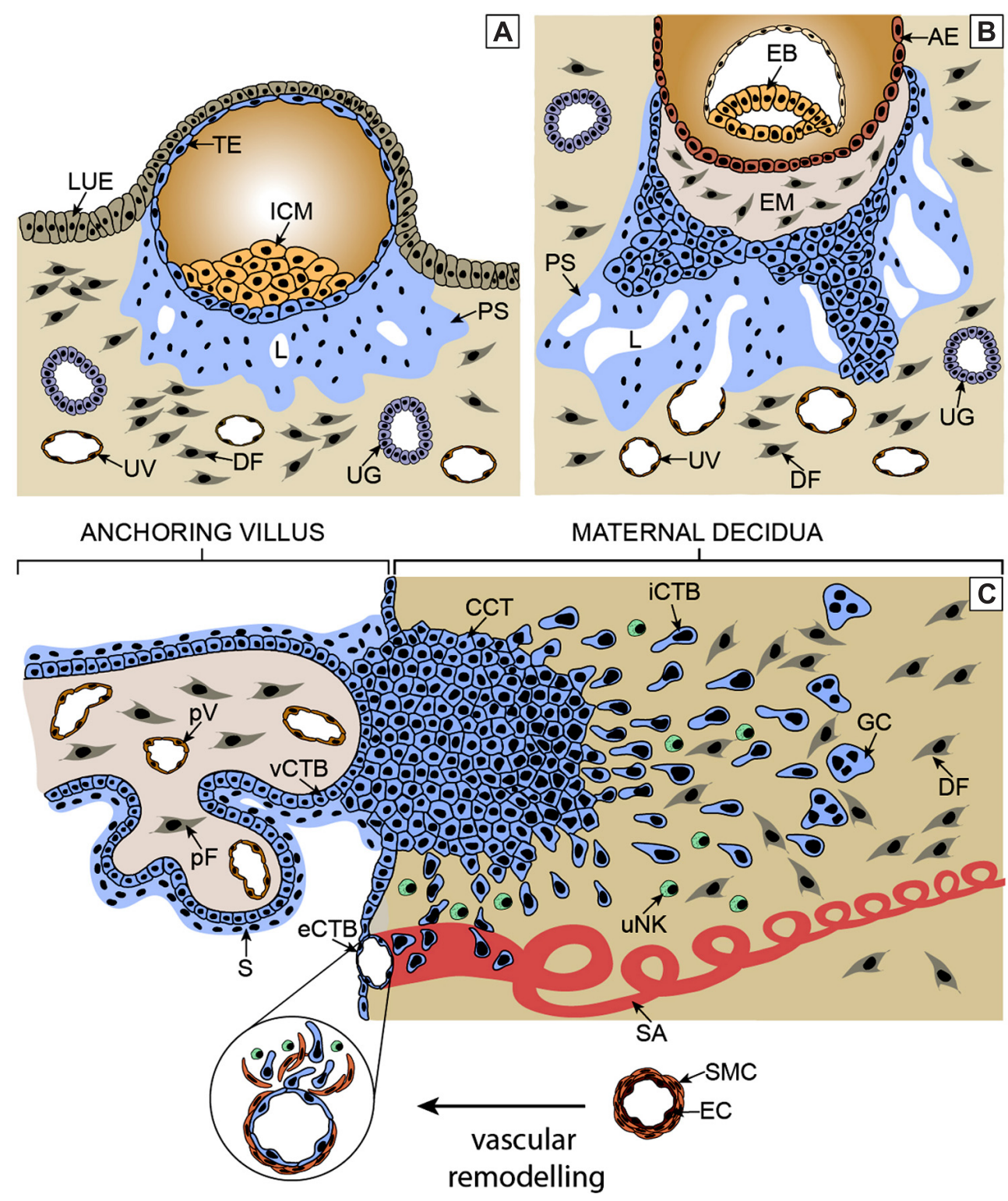

FIGURE 1 | Critical steps of human placental development. (A) After implantation stems cells of the trophectoderm give rise to the primitive syncytium by cell fusion. In this region lacunae, the ancestor of the intervillous space, are formed. Some of the lacunae erode uterine vessels. (B) At a subsequent stage, proliferative cytotrophoblasts (CTBs) emanate from the trophectoderm, break through the primitive syncytium and contact the basal plate thereby forming primary villi. (C) Tertiary villi are built upon migration of extraembryonic mesodermal cells into the primary structures and vascularization. At distal sites, proliferative cell columns are formed which give rise to different invasive extravillous trophoblast subtypes. iCTBs migrate into decidual stroma approach vessels from outside and eventually form giant cells as the end stage of the invasive differentiation pathway. Endovascular trophoblasts migrate into spiral arteries and contribute to UNK cell-initiated remodeling within the decidua and the upper part of the myometrium. $A E$, amniotic epithelium; CCT, cell column trophoblast; DF, decidual fibroblast; EB, embryoblast; EM, extraembryonic mesoderm; eCTB, endovascular cytotrophoblast; GC, giant cell; ICM, inner cell mass, iCTB, interstitial cytotrophoblast; LUE, luminal uterine epithelium; L, lacunae, pF, placental fibroblast; PS, primitive syncytium; pV, placental vessel; SA, spiral artery; $S$, syncytium; TE, trophectoderm; UG, uterine gland; UNK, uterine NK cell; UV, uterine vessel; VCTB, villous cytotrophoblast. maternal decidua likely cross-talking to diverse uterine cell types, including uterine natural killer cells, macrophages, and decidual stromal cells (Bulmer et al., 2010; Oreshkova et al., 2012). These interactions are thought to be important for immunological acceptance of the placental/fetal allograft as well as for the timing and depth of trophoblast invasion (Redman and Sargent,
2010). In particular, interaction of paternal human leukocyte antigen (HLA)-C expressed on iCTBs with maternal killer cell immunoglobulin-like receptors (KIR) are thought to play a pivotal role in placentation and reproductive success (Hiby et al., 2004). In the absence of blood flow, trophoblast invasion might be controlled by factors secreted from uterine glands, such as 
epidermal growth factor (EGF) and vascular endothelial growth factor (vEGF), which are also thought to be crucial for placental and embryonic growth at this early stage of pregnancy (Burton et al., 2007). With the establishment of the maternalplacental circulation, the placenta switches from histiotrophic to haemotrophic nutrition around the 12th week of gestation, plugging of vessels is dissolved and extensive remodeling occurs. Transformation of the maternal spiral arteries into large diameter vessels likely ensures adapted nutrient supply, reduced vessel contractility and constant oxygen delivery at low blood pressure to the developing fetus (Burton et al., 2010). Vessel remodeling might be initiated by uterine NK cells and both types of differentiated EVTs are thought to play a crucial role in completing this process (Robson et al., 2012). Whereas eCTBs displace maternal endothelial cells and remodel decidual and superficial myometrial spiral arteries, iCTBs approach the vessels from outside and contribute to elastolysis and disruption of the vascular wall. This involves a series of events such as trophoblast-induced apoptosis of vascular smooth muscle cells (Harris, 2011). Failures in EVT invasion, remodeling and CTB gene expression were noticed in different pregnancy diseases such as preeclampsia or severe intrauterine growth restriction (Pijnenborg et al., 1991, 2006; Zhou et al., 2013). Abnormal contractility and pressure may provoke hypoxia re-oxygenation injuries of floating villi thereby inducing secretion of adverse cytokines and antiangiogenic molecules such as soluble Fms-like tyrosine kinase-1 (sFLT-1) and elevated shedding of syncytiotrophoblast microparticles (Burton et al., 2010; Redman et al., 2012; Tal, 2012). The latter are thought to contribute to maternal endothelial cell dysfunction as part of a global, systemic inflammatory response observed in preeclampsia.

\section{DIFFERENTIATION AND INVASION OF HUMAN EXTRAVILLOUS TROPHOBLAST}

Differentiation of proliferative CTBs into growth-arrested EVTs, invading decidual tissue and vessels, is thought to involve a series of well-controlled molecular steps which, however, are poorly understood. This is partly due to the fact that EVT differentiation in vitro can only be studied upon access to first trimester placental samples, which in general is limited due to ethical considerations. Growth of the trophoblast cell column harboring progenitor cells for the invasive differentiation pathway may involve paracrine factors released from the underlying placental mesenchyme such as IGF molecules which also promote proliferation of vCTBs in vitro (Aplin et al., 2000; Forbes et al., 2008). Since spontaneous outgrowth and migration in villous explant cultures is achieved in the absence of serum, it is likely that the intrinsic molecular program of the placental villus is also sufficient for the particular differentiation process in vivo. However, the precise mechanisms controlling integrity and stability of cell columns allowing for balanced rates of growth and differentiation have not yet been elucidated. Adhesive interactions between L-selectin expressed in cell columns and its carbohydrate ligands could play a role (Prakobphol et al., 2006). Moreover, different transcription factors such as oxygen-dependent hypoxia-inducible factor $1 \alpha(\mathrm{HIF} 1 \alpha)$ and Stox 1 , discussed elsewhere in this issue, are critical for trophoblast cell proliferation and inhibit differentiation into EVTs (Caniggia et al., 2000b; van Dijk and Oudejans, 2011). In contrast, AP- $2 \alpha$, signal transducer and activator of transcription 3 (STAT3) or glial cells missing 1 (GCM1) promote trophoblast invasion and GCM1 was also shown to inhibit proliferation of vCTBs (Poehlmann et al., 2005; Baczyk et al., 2009; Biadasiewicz et al., 2011). Hence, it is assumed that a set of key regulatory transcription factors controls the switch between trophoblast proliferation and EVT differentiation (Loregger et al., 2003; Knöfler and Pollheimer, 2012). EVT formation is accompanied by the expression of distinct intergrins which are induced in a distance-dependent manner in vivo as well as in vitro (Damsky et al., 1994; Aplin et al., 1999). Again, the molecular basis for differentiation-dependent integrin switching remains unknown. Increasing oxygen concentrations during pregnancy and contact with the decidual matrix likely play major roles. Interestingly, accumulating evidence suggests that failures in EVT differentiation could contribute to the pathogenesis of pregnancy diseases with restricted trophoblast invasion and remodeling. Expression of inhibitor of DNA binding 2 (Id2), blocking the binding activity of differentiation-promoting basic helix-loop-helix (bHLH) proteins through heterodimerisation, was shown to be downregulated in EVTs of normal pregnancy but maintained in preeclamptic placental tissue (Janatpour et al., 2000). Along those lines, inhibition of HIF1 $\alpha$-dependent TGF $\beta 3$, acting as a negative regulator of trophoblast invasion, restored migration in explant cultures of preeclamptic villi emphasizing the particular role of oxygen in EVT differentiation (Caniggia et al., 1999, 2000a). Moreover, upregulation of EVT-specific genes and invasion were impaired in trophoblasts isolated from preeclamptic placentae (Lim et al., 1997). Of importance, eCTBs express a characteristic pattern of vascular adhesion molecules which, however, is abnormal in preeclamptic tissues (Zhou et al., 1997a).

While the hierarchy and cross-talk of critical molecular events controlling EVT differentiation await further investigations, regulation of trophoblast invasion has been investigated in a vast number of studies using primary cells, choriocarcinoma cells and established non-tumorigenic trophoblast cell lines. The different invasive trophoblast cell types produce sets of proteases, i.e., matrix metalloproteinases (MMP), urokinase plasminogen activator (uPA) and cathepsins, which are thought to degrade decidual extracellular matrix proteins and thereby facilitate cell invasiveness. The respective inhibitors, tissue inhibitors of metalloproteinases (TIMPs) and plasminogen activator inhibitors (PAIs) are produced by EVTs as well as decidual cells to limit the extent of trophoblast invasion. Numerous soluble factors expressed at the fetal-maternal interface including chemokines, cytokines and angiogenic factors were shown to promote trophoblast motility in an autocrine or paracrine manner (Bischof et al., 2000; Lala and Chakraborty, 2003; Knöfler, 2010). As a common theme, the secreted proteins were shown to stimulate MMP expression and secretion, in particular the gelatinases MMP- 2 and MMP-9. Inhibitory proteins such as TNF, Nodal or TGF $\beta$ could restrain trophoblast motility by increasing expression of TIMPs and PAIs (Lala and Graham, 1990; Haider and Knöfler, 2009; Nadeem et al., 2011). Although a complex interplay of growth factors likely controls trophoblast cell migration and invasion, it remains unclear whether all of the currently identified effects truly play a role in vivo. Tumorigenic and non-tumorigenic cell types as 
well as hybridomas used in functional studies may not accurately mimic trophoblast cell behavior. Indeed, overall gene expression profiles of primary CTBs and EVT cultures differ considerably from the different established trophoblast cell lines (Bilban et al., 2010). Moreover, compared to primary cells, a diverging HLA profile was identified in the immortalized trophoblast cell lines. Villous CTBs lack surface expression of classical HLA molecules, but EVTs produce HLA-C, -E, and -G upon differentiation. JEG-3 choriocarcinoma cells show a similar HLA profile as EVTs, whereas several immortalized cell lines produce HLA-A and -B, suggesting abnormal activation of these genes during the immortalization procedure or a non-trophoblastic origin of these cells (Apps et al., 2009).

Furthermore, published literature suggests key signaling pathways that are involved in trophoblast motility. Abundant growth factors such as hCG, EGF, HGF, or IGF2 activate MAPK kinase (MEK)/extracellular regulated kinase (ERK) and phosphoinositide 3-kinase (PI3K)/AKT/mammalian target of rapamycin (mTOR) signaling, whereas prostaglandins were shown to act through the Rho-Rock pathway (Pollheimer and Knöfler, 2005; Knöfler, 2010). Besides expression of TIMPs and PAIs, downregulation of signaling kinase activity could represent a mechanism to limit the extent of trophoblast invasion. For example endostatin, which could be released from decidual collagen XVIII by EVT-mediated proteolytic cleavage, was shown to impair growth factor-induced AKT/mTOR phosphorylation and cell migration (Pollheimer et al., 2004, 2005, 2011).

To identify novel genes and pathways controlling trophoblast motility and differentiation we and others recently performed comparative gene expression studies of CTBs and EVTs isolated from first trimester placental tissues. Chip-based profiling of EGFR-positive CTBs, isolated by flow cytometry, and EVTs, generated by seeding of the CTBs on fibronectin for $12 \mathrm{~h}$, resulted in the identification of 3433 mRNAs which are at least two-fold differentially expressed between the two cell populations (Apps et al., 2011). Using immunopurified CTBs and EVTs isolated from outgrowths of villous explant cultures and gene chips with a lower number of probe sets compared to the aforementioned study, we detected 991 differentially expressed transcripts in our analyses (Bilban et al., 2009). One of these mRNAs which was found to be induced upon EVT differentiation encoded TCF-4, one of the key transcription factors in Wnt signaling (Roose and Clevers, 1999). Hence, this result prompted us to investigate the expression pattern of Wnt signaling components and the general role of the canonical signaling pathway in human trophoblast migration and invasion.

\section{Wnt SIGNALING PATHWAYS}

Besides Hippo, Hedgehog, Notch and TGF $\beta$ signaling, Wnt signaling represents one of the few conserved pathways critically involved in developmental processes. From Drosophila to human, the particular signal transduction cascade controls early axis formation, limb patterning and organogenesis (Logan and Nusse, 2004; Clevers, 2006). In adults, Wnt controls homeostasis of regenerating tissues such by regulating stem cell maintenance, cell fate decisions and differentiation (Clevers, 2006; Herr et al., 2012). Abnormal Wnt signaling has been described in a variety of human diseases including different cancers, diabetes or neurodegenerative disorders (Polakis, 2000; Al-Harthi, 2012). Wnts comprise a family of palmitoylated, cysteine-rich glycoproteins, which due to their low solubility are secreted in a lipoprotein-bound form or through exosomes (Herr et al., 2012). The first described member of this family of secreted ligands was the Wntl proto-oncogene, which is homologous to the Drosophila gene Wingless. Originally, the gene has been named int-1 since it has been identified as an integration site for the murine mammary tumor virus which can provoke breast cancer (Nusse et al., 1991). In humans, 19 different Wnt ligands and 10 seven-transmembrane domain frizzled (Fzd) receptors have been identified (Wodarz and Nusse, 1998). The latter interact with low density lipoprotein receptor related proteins (LRP-5 or -6) forming a functional, heterodimeric receptor for canonical Wnt signaling. It is likely that the complex interplay of different Wnts with Fzds provokes specific Wnt responses depending on the receptor context and the particular cell type. Stabilization and nuclear recruitment of $\beta$-catenin is a hallmark of the canonical pathway. However, Wnt ligands also trigger non-canonical, $\beta$-catenin-independent signaling including the Wnt/ $\mathrm{Ca}^{2+}$ and the Wnt/planar cell polarity (PCP) pathway (Gordon and Nusse, 2006; Hendrickx and Leyns, 2008; van Amerongen and Nusse, 2009).

\section{CANONICAL Wnt SIGNALING}

Canonical Wnt signaling involves a series of steps resulting in the stabilization and nuclear translocation of $\beta$-catenin (Gordon and Nusse, 2006). In unstimulated cells, $\beta$-catenin is predominantly found at adherens junctions where it binds to E-cadherin and $\alpha$-catenin and thereby maintains epithelial structure and polarity. Cytosolic levels of $\beta$-catenin are low since it is degraded in a destruction complex consisting of adenomatous polyposis coli (APC), Axin, casein kinase I $\alpha(\mathrm{CKI} \alpha)$ and glycogen synthase kinase $3 \beta$ (GSK-3 $\beta$ ). The latter phosphorylates $\beta$-catenin at its $\mathrm{N}$-terminus and thereby induces binding of $\beta$-transducin repeatcontaining protein $(\beta-\operatorname{TrCP})$ and its associated $\mathrm{E} 3$ ubiquitin ligase. This results in ubiquitination and proteasomal degradation of $\beta$-catenin (Stamos and Weis, 2013). In contrast, Wnt stimulation promotes Fzd-LRP heterodimerisation and cytosolic stabilization of $\beta$-catenin by disruption of the APC/Axin/GSK-3 $\beta / C K 1 \alpha$ destruction complex. Upon binding of Wnt to the cysteine-rich domain of Fzd, the multifunctional protein Disheveled (Dvl) is recruited to the cytosolic portion of the heterodimeric receptor and thereby provokes binding of Axin and GSK-3 $\beta$ as well as GSK-3 $\beta$-mediated phosphorylation of LRP-5/6 (Mao et al., 2001; Bilic etal., 2007). This event could either inhibit the catalytic activity of GSK-3 $\beta$ toward $\beta$-catenin promoting sequestration or induce internalization and lysosomal degradation of components of the destruction complex (Metcalfe and Bienz, 2011). As a consequence cytoplasmic concentrations of $\beta$-catenin increase and active de-phosphorylated $\beta$-catenin translocates to the nucleus where it binds to transcription factors of the lymphoid enhancer factor-1 (LEF-1)/TCF family (Clevers, 2006; Gordon and Nusse, 2006). LEF/TCF proteins are high mobility group proteins lacking transcriptional activity and hence require coactivators or co-repressors for their function. Binding of $\beta$-catenin to LEF/TCF converts these proteins into transcriptional activators 
by displacing histone deacetylases (HDACs) and inhibitors of the Groucho protein family followed by recruitment of the Legless family docking protein $\mathrm{Bcl} 9, \mathrm{CBP} / \mathrm{p} 300$ and histone acetylases (Gordon and Nusse, 2006; Archbold et al., 2012). Activation of LEF-1/TCF then provokes transcription of numerous genes controlling developmental processes, cell cycle, differentiation and cell invasion such as cyclin D1, c-myc, c-jun, MMPs, urokinase plasminogen activator receptor (uPAR), Notch signaling factors and many others depicted at the Wnt homepage ${ }^{1}$. Moreover, Wnt signaling components such as Axin, TCFs or Fzds are often controlled by a feedback loop upon Wnt activation. Accumulating evidence, however, suggests that our view of canonical Wnt signaling is still too simplistic. Proteins of the destruction complex can enter the nucleus and influence trafficking of Wnt signaling components as well as gene transcription. Numerous soluble negative regulators of Wnt signaling such as different Dickkopf (Dkk) or secreted frizzled-related proteins (sFRPs) binding to Wnts and LRP, respectively, have been identified (Gordon and Nusse, 2006). TCFs interact with several other regulatory transcription factors, for example Smads, c-jun or Cdx proteins, likely determining specificity of binding to $\mathrm{W} n \mathrm{t}$ response elements (Archbold et al., 2012). Moreover, TCF/ $\beta$-catenin transcriptional complexes can also repress transcription and $\beta$-catenin can be recruited to other transcription factors than LEF/TCF, e.g., steroid hormone receptors, in a Wnt-dependent manner (Beildeck et al., 2010).

Several alterations in Wnt signaling components have been detected in cancer cells provoking nuclear accumulation of $\beta$ catenin and aberrant Wnt signaling (Camilli and Weeraratna, 2010). While mutations in Wnt ligands are rare, mutations in the APC tumor suppressor gene have been identified in the majority of sporadic colorectal cancers. Moreover, activating mutations in $\beta$-catenin inhibiting its GSK-3 $\beta$-dependent degradation were detected in colon, prostate and other malign tumors. In addition, there is also compelling evidence that epigenetic changes of the Wnt pathway contribute to tumorigenesis since downregulation of sFRP gene transcription through promoter methylation has been observed in different epithelial cancers (Herr et al., 2012).

\section{NON-CANONICAL Wnt SIGNALING}

The fact that different Wnts can exert effects on cells independently of $\beta$-catenin adds further complexity to the particular signaling pathway. Ligands such as Wnt5a or Wnt11 can activate the Wnt/PCP and the Wnt/Ca ${ }^{2+}$ pathway by binding to Fzds and activating Dvl independently of LRP-5 or -6 (Komiya and Habas, 2008). Induction of Wnt/PCP signaling, originally identified in different developmental processes of Drosophila, involves the G-proteins Rac and RhoA and the downstream effectors c-jun $\mathrm{NH}_{2}$-terminal kinase (JNK) and Rho-associated kinase (ROCK), respectively. Wnt/PCP signaling is critically involved in the formation of embryonic tissues and organs and aberrant activation of the pathway was shown to promote metastasis of different cancer types (Wang, 2009).

On the other hand, Wnt/Ca ${ }^{2+}$ signaling inhibits cGMPdependent protein kinase (PKG), which blocks $\mathrm{Ca}^{2+}$ release in unstimulated cells and activates phospholipase C (PLC) and

${ }^{1}$ http://www.stanford.edu/ rnusse/wntwindow.html elevation of inositol 1,4,5-trisphosphate $\left(\mathrm{IP}_{3}\right)$ thereby releasing $\mathrm{Ca}^{2+}$ from the endoplasmic reticulum (Kohn and Moon, 2005). Increased cytosolic $\mathrm{Ca}^{2+}$ levels finally stimulate activity of protein kinase C (PKC), calcium/calmodulin-dependent kinase II (CamKII) and calcineurin which provoke nuclear recruitment of nuclear factor $\kappa \mathrm{B}(\mathrm{NF} \kappa \mathrm{B})$ and of nuclear factor of activated $\mathrm{T}$ cells (NF-AT) (Saneyoshi et al., 2002; Ma and Wang, 2006; De, 2011). In addition, $\mathrm{Ca}^{2+}$ accumulation upon Wnt5a stimulation can induce TGF- $\beta$-activated kinase (TAK1) and Nemo-like kinase (NEMO), which block TCF through phosphorylation and antagonize canonical Wnt signaling (Ishitani et al., 1999; Ishitani and Ishitani, 2013). Hence, in some cancers Wnt5a acts as a tumor suppressor. However, the effects of Wnt5a strongly depend on the receptor context. Binding to Fzd2, 3, 5, 6 induces $\mathrm{Ca}^{2+}$ signaling, but the ligand can also activate the canonical pathway upon interaction with Fzd4 and LRP (Mikels and Nusse, 2006; Nishita et al., 2010). Moreover, various studies suggest that different Wnts can interact with the receptor tyrosine kinases Ryk and Ror2 and promote developmental processes independently of Fzd or activate classical signaling pathways such as ERK or PI3K/AKT/mTOR (Yun et al., 2005; Kim et al., 2007; Fradkin et al., 2010; Minami et al., 2010). In conclusion, Wnts binding to canonical and diverse non-canonical receptors form a highly complex signaling network with a considerable overlap between the different pathways.

\section{Wnt SIGNALING IN PLACENTA AND TROPHOBLAST}

As outlined above and discussed elsewhere, early placental development is associated with rapid generation of several trophoblast subtypes forming distinct functional villi in mice and men (Georgiades et al., 2002; Red-Horse et al., 2004). Likewise, the maternal uterus adapts to pregnancy by extensive tissue remodeling involving differentiation of stromal cells, angiogenesis and immunological alterations. These critical processes are initiated during the secretory phase of the menstrual cycle and upon implantation and early stages of placental development. Given the fact that Wnt signaling is important for organ development and tissue homeostasis, it may not be surprising that the pathway also has major roles in uterus formation, growth and differentiation. Gene targeting in mice revealed that $\beta$-catenin and different Wnts, such as Wnt4, Wnt5a, or Wnt7a, are critical for uterine development (Miller and Sassoon, 1998; Vainio et al., 1999; Mericskay et al., 2004; Arango et al., 2005). Wnt signaling components also play a role in stroma cell proliferation and differentiation for example Wnt4, Wnt6 (Li et al., 2013; Wang et al., 2013) or Dkk1, a progesterone-regulated gene which is induced in the endometrium upon decidualization (Tulac et al., 2006; Duncan et al., 2011).

This review focuses on function of Wnt signaling in trophoblast and placental development and differentiation, whereas a number of different papers summarize the role of canonical and noncanonical Wnt signaling in female reproductive tract development and differentiation, uterine function and decidualization (Chen et al., 2009; Sonderegger et al., 2010b; van der Horst et al., 2012; Wetendorf and DeMayo, 2012).

\section{Wnt SIGNALING IN MURINE PLACENTAL DEVELOPMENT}

Expression of several Wnt ligands, Fzds and Dvl proteins has been noticed in the developing murine blastocyst during the 
pre-implantation period (Mohamed et al., 2004; Harwood et al., 2008). However, the canonical pathway does not seem to play a role in blastocyst formation. Embryos bearing homozygous deletion of $\beta$-catenin develop to the blastocyst stage but are affected upon gastrulation (Haegel et al., 1995). However, maternal $\beta$-catenin may have compensated the lack of embryonic $\beta$-catenin. Therefore, mothers harboring a conditional deletion of the gene in oocytes were additionally used in $\beta$-catenin knock-out studies (De Vries et al., 2004). Again, development into blastocysts was observed suggesting that $\beta$-catenin is not required for early pre-implantation development. Also, treatment with Dkk1 did not impair blastocyst formation (Xie et al., 2008). Non-canonical signaling such as the $\mathrm{Wnt} / \mathrm{Ca}^{2+}$ pathway could be involved (Chen et al., 2009). On the other hand, there is evidence that the canonical Wnt pathway could regulate blastocyst development in other species for example in ruminants (Denicol et al., 2013).

Whereas the canonical Wnt pathway is dispensable for murine blastocyst development, it is critical for blastocyst activation, adhesion and implantation. Inhibition of the pathway through Dkk1 or small molecular inhibitors decreased implantation, which was also shown to be associated with induction of canonical $\beta$-catenin and downregulation of non-canonical Wnt-RhoA signaling (Xie et al., 2008). Likewise, treatment with sFRP2 was shown to decrease implantation rates (Mohamed etal., 2005). Induction of the canonical pathway in the uterine epithelium and myometrial smooth muscle cells at the site of implantation through trophectoderm-derived Wnt ligands seems to be important (Mohamed et al., 2005).

Wnt signaling could also play a key role during early trophoblast development in mice. Treatment of embryonic stem cells with Wnt3a induced formation of trophectodermal stem cells with the capacity to differentiate into spongiotrophoblasts and giant cells which was mediated through LEF-1-dependent induction of $\mathrm{Cdx} 2$, a key regulator of early trophoblast lineage determination (Chawengsaksophak et al., 2004; He et al., 2008).

Furthermore, gene targeting in mice provided evidence that Wnt signaling components control sequential steps of placental development. In particular, chorioallantoic fusion, branching morphogenesis, labyrinth development and placental angiogenesis were affected in these mutants (Cross et al., 2006). For example, gene knock-outs of Wnt7b, R-spondin3, a soluble activator of canonical Wnt signaling, or of both TCF-1 and LEF-1 show defects in chorioallantoic fusion thereby altering normal labyrinth development and function at later stages of embryogenesis (Galceran etal., 1999; Parr etal., 2001; Aoki et al., 2007). Similar to the above mentioned mutants, homozygous deletion of Wnt2 and Fzd5 affected branching and labyrinth formation, however, without alterations in chorioallantoic fusion (Monkley et al., 1996; Ishikawa et al., 2001). Moreover, placentae lacking Bcl-9, one of the co-activators of LEF-1/TCF, showed defective branchpoint initiation and a decrease in syncytiotrophoblast formation (Matsuura et al., 2011). GCM1, the key transcription factor in branching morphogenesis and trophoblast cell fusion (Anson-Cartwright et al., 2000), is probably the most critical Wnt target in mouse placental development since diminished expression of GCM1 was noticed in R-spondin3 and Bcl-9-mutant placentae (Aoki et al., 2007; Matsuura et al., 2011). Indeed, a recent study indicated that a positive feedback loop of Fzd5 and GCM1 controls different steps of placental morphogenesis promoting branchpoint initiation, chorionic trophoblast-specific vEGF expression and trophoblast syncytialisation (Lu et al., 2013). Placental phenotypes of mice with homozygous deletions of Wnt signaling genes are summarized in Table 1. Early stages of murine trophoblast invasion, however, might be negatively affected by canonical Wnt signaling since recombinant Dkk1 was shown to increase motility in co-cultivations of ectoplacental cones with decidual cells (Peng et al., 2008).

\section{EXPRESSION PATTERNS OF Wnt LIGANDS AND FRIZZLED RECEPTORS IN HUMAN TROPHOBLASTS}

Human trophoblast development is mostly studied in choriocarcinoma model systems and immortalized trophoblast cell lines, since primary placental material can only be obtained from very restricted time points during pregnancy. Trophoblast cell fusion can be investigated in isolated term CTBs involving numerous effectors (Morrish et al., 1998). Invasive properties of cells are lost at the end of pregnancy and therefore trophoblast motility and differentiation of progenitors into EVTs has to be analyzed in first trimester placentae using villous explant cultures and/or isolated CTBs (Pollheimer and Knöfler, 2005). Investigations in these primary cultures as well as in cell lines provided evidence for an autocrine role of Wnt signaling in human trophoblast proliferation and invasion (Sonderegger et al., 2010b). As a first step, our laboratory analyzed the expression patterns of all Wnt ligands and Fzd receptors in different trophoblast cell lines, isolated CTBs and

Table 1 | Placental phenotypes of mice with homozygous deletion of Wnt signaling components.

\begin{tabular}{lll}
\hline $\begin{array}{l}\text { Gene } \\
\text { knock-out }\end{array}$ & Phenotype & Reference \\
\hline Wnt2 & $\begin{array}{l}\text { Defects in labyrinthine zone } \\
\text { Decreased number of fetal capillaries } \\
\end{array}$ & $\begin{array}{l}\text { Monkley et al. } \\
\text { Oedema formation }\end{array}$ \\
& Fibrinoid deposition
\end{tabular}

Wnt7b

Defect in alpha4-mediated

Parr et al. (2001)

chorioallantoic fusion

Disorganization of chorionic plate

R-spondin3 Defects in chorioallantoic fusion,

Aoki etal. (2007)

branching and labyrinth formation

Reduced expression of $\mathrm{Gcm} 1$

Fzd5 Defects in yolk sac angiogenesis and

placental vasculogenesis

Defective chorioallantoic branching

Decreased GCM1 expression

Bcl9 Defective branching initiation

Failures in trophoblast syncytialisation

LEF-1/TCF-1 Defects in chorioallantoic fusion

Ishikawa et al.

(2001); Lu etal.

(2013)

Matsuura etal.

(2011)

Galceran et al.

(1999) 
total placental extracts of first and third trimester, as well as in villi and EVTs obtained from first trimester villous explant cultures using optimized, semi-quantitative RT-PCR (Sonderegger et al., 2007). 14 out of 19 Wnt ligands, and 8 out of 10 Fzd receptors were found to be expressed in total first trimester placenta. Most of these mRNAs were detectable in the villous trophoblast epithelium. In particular, abundantly (Wnt1, Wnt2b, Wnt4, Wnt7b, Wnt10a, Wnt10b, Wnt11), moderately (Wnt5a, Wnt9b) and lowly (Wnt2, Wnt3, Wnt5b, Wnt6, Wnt7a) -expressed Wnt ligands were present in first trimester CTBs as depicted (Figure 2). Hence, expression of canonical (for example Wnt1, Wnt2b, Wnt7b, Wnt10a, Wnt10b) as well as non-canonical Wnts (Wnt4, Wnt5a, Wnt11) suggests that different Wnt pathways may operate during human trophoblast development. Wnt1, Wnt7b, Wnt10a, and Wnt10b were downregulated from first trimester to term suggesting roles in trophoblasts of early pregnancy (Sonderegger et al., 2007). Whereas Fzd 2 and Fzd4 are only produced in villous mesenchymal cells, Fzd1, Fzd3, Fzd5, Fzd6, Fzd7, and Fzd10 are expressed in CTBs. The latter was absent from villous fibroblasts suggesting a specific role in CTBs. Although none of the individual Wnts and Fzds have been studied in the context of human trophoblast invasion and differentiation so far, expression patterns and comparison to the situation in mouse placenta and other Wnt-dependent systems in reproduction allows to speculate about their potential roles.

Wnt 4 is produced by CTBs as well as EVTs and could contribute to decidualization through the canonical pathway (Li et al., 2013). Wnt5a, secreted from trophoblast cell lines and primary cultures, may act through non-canonical pathways since it was unable

\begin{tabular}{|c|c|}
\hline & CTB \\
\hline Wnt1 & \\
\hline Wnt2 & \\
\hline Wnt2b & \\
\hline Wnt3 & \\
\hline Wnt4 & \\
\hline Wnt5a & \\
\hline Wnt5b & \\
\hline Wnt6 & \\
\hline Wnt7a & \\
\hline Wnt7b & \\
\hline Wnt9b & \\
\hline Wnt10a & \\
\hline Wnt10b & \\
\hline Wnt11 & \\
\hline Fzd1 & \\
\hline Fzd3 & \\
\hline Fzd5 & \\
\hline Fzd6 & \\
\hline Fzd7 & \\
\hline Fzd10 & \\
\hline
\end{tabular}

FIGURE 2 | Schematic illustration of transcript levels encoding Wnt ligands and Fzd receptors in isolated human first trimester CTBs and EVTs measured by semi-quantitative RT-PCR as published elsewhere (Sonderegger et al., 2007). Low, medium and high levels of expression are indicated by one, two and three black squares, respectively. to induce TCF/ $\beta$-catenin-dependent transcription but antagonized the canonical pathway in trophoblasts (Sonderegger et al., 2007). Progesterone treatment of ovariectomized mice was shown to stimulate Wnt11 expression, another non-canonical Wnt ligand, whereas Wnt4 and Wnt7b are induced by estrogen which likely has implications for implantation (Hayashi et al., 2009) and decidualization as mentioned above. Interestingly, Wnt4, Wnt11 and $\mathrm{Wnt} 7 \mathrm{~b}$ are among the most abundantly produced Wnts in CTBs and Wnt7b expression decreased during EVT formation (Figure 2). Considering that Wnt7b is required for mouse placental development (Parr et al., 2001), the human homologue may also play a role in placenta formation and/or control critical functions during the first trimester of pregnancy such as trophoblast proliferation. Similarly, Wnt10a, Wnt10b, Fzd5, and Fzd10 were strongly expressed in CTBs but largely absent from EVTs or placental fibroblasts suggesting that these Wnt and Fzd members are also predominantly associated with early trophoblast cell growth. The principal Fzd receptor in EVTs is Fzd6, which operates through canonical as well as non-canonical pathways (Golan et al., 2004; Wu et al., 2009). Differential expression of Fzds between CTBs and EVTs is also detectable in our previously established gene expression profiles (Bilban et al., 2009) as shown in Figure 3. Whereas the role of Wnt10a, Wnt10b or FZD10 in murine placental development is unknown, Fzd5 is critical for branching morphogenesis as mentioned before (Lu et al., 2013). Hence, Fzd5 could also play a crucial role in human placental development. Furthermore, another semi-quantitative RT-PCR study suggested that several of the above mentioned Wnt ligands are regulated in a gestationdependent manner in first trimester placenta (Grisaru-Granovsky et al., 2009) suggesting that specific combinations of Wnts could eventually control sequential steps of human trophoblast function and/or development. Moreover, the endometrial Wnt ligands Wnt2, Wnt4, Wnt5a, Wnt7a, Wnt8b, and Wnt3, the latter being regulated during the menstrual cycle, could affect trophoblast function in a paracrine manner (Tulac et al., 2003).

\section{Wnt SIGNALING IN HUMAN TROPHOBLAST FUNCTION AND DIFFERENTIATION}

Studies in mice suggested that Wnt signaling is critical for activation and implantation of blastocysts (Mohamed et al., 2005). In vitro investigations with trophoblast cell lines and cultures also revealed a role of the particular signaling pathway in human trophoblast adhesion, invasion and differentiation.

Treatment of decidualized stromal cells with supernatants of trophoblasts provoked changes in the expression of some Wnt signaling components suggesting that soluble trophoblast-derived factors could influence endometrial function and differentiation through regulation of the Wnt pathway (Hess et al., 2007). Different Wnts secreted from EVTs could be the prime factors controlling expression of decidual Wnt signaling components since many of these genes are direct targets of TCF $/ \beta$-catenin as summarized at the Wnt homepage ${ }^{1}$. Along those lines, attachment of spheroids prepared from JAR choriocarcinoma cells to endometrial Ishikawa cells was inhibited in the presence of Dkk1 (Liu et al., 2010). Similarly, 2,3,7,8-tetrachlorodibenzo-p-dioxin (TCDD), a negative effector of implantation, decreased attachment of JEG-3 or BeWo cell spheroids to different endometrial epithelial cell lines 


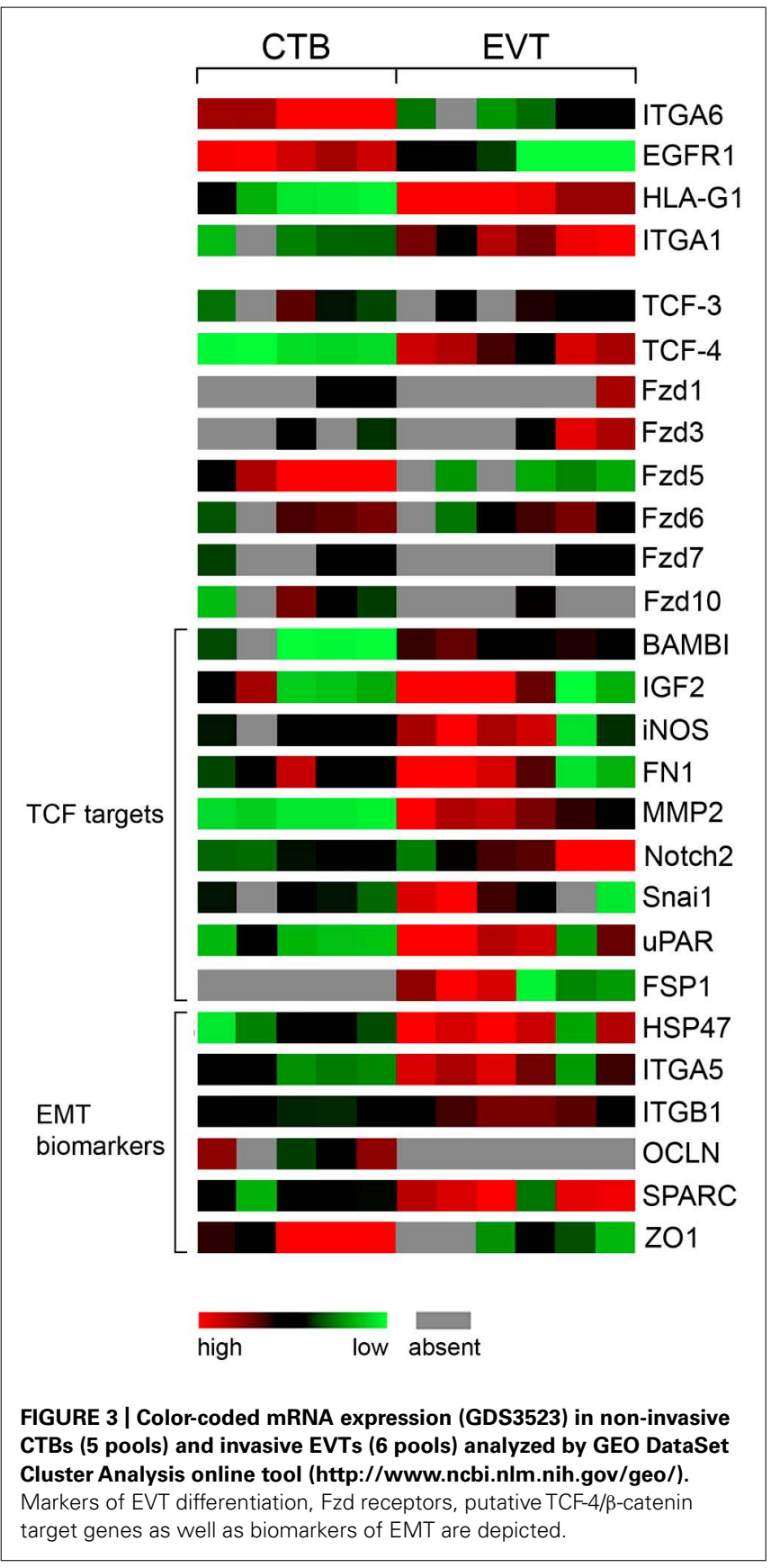

by suppressing $\beta$-catenin, which could be reverted upon treatment with a recombinant Wnt ligand (Tsang et al., 2012).

Moreover, expression analyses of TCFs in human first trimester placenta suggested that the canonical Wnt pathway is associated with the invasive differentiation process of trophoblasts (Pollheimer et al., 2006). Immunofluorescence of tissues revealed induction of TCF-4 protein in the nucleus of non-proliferating, p57/KIP2-positive EVTs as well as nuclear recruitment of $\beta$ catenin in a considerable number of these cells. Analyses of our expression profiles performed with total mRNA isolated from five and six different CTB and EVT cell preparations, respectively (Bilban et al., 2009), suggested induction of TCF-4 at the mRNA level (Figure 3). Moreover, stimulation with a Wnt ligand increased invasion of primary CTBs and trophoblastic SGHPL5 cells in transwell assays and promoted migration in villous explant cultures seeded on collagen I, which was inhibited upon treatment with recombinant Dkk1 (Pollheimer et al., 2006; Sonderegger et al., 2010a). In addition, basal migration and invasion of the different trophoblast models were reduced in the presence of Dkk1 suggesting that the aforementioned canonical Wnts expressed in EVTs exert autocrine effects. Wnt stimulation was also shown to activate non-canonical AKT signaling and AKTdependent motility of trophoblasts (Sonderegger et al., 2010a). Canonical LRP-5/6-FZD receptors were not involved since Wntdependent phosphorylation of AKT could not be inhibited upon supplementation of Dkk1. Also, cross-talk between the canonical Wnt pathway and AKT through AKT-induced phosphorylation and inactivation of GSK-3 $\beta$ as mentioned for other cells (Naito et al., 2005) has not been observed in trophoblasts since chemical AKT inhibitors did neither change nuclear accumulation of $\beta$ catenin nor the activity of a canonical Wnt reporter (Sonderegger et al., 2010a). One of the putative targets increasing invasiveness in a Wnt-dependent manner could be MMP-2, which is elevated in trophoblast supernatants upon Wnt stimulation and also has been described as a direct target of TCF/ $\beta$-catenin (Wu et al., 2007; Sonderegger et al., 2010a). Although MMP-2 mRNA expression is associated with EVT differentiation (Figure 3), transcript levels did not change upon Wnt stimulation suggesting that the pathway induces MMP-2 secretion or affects its stability (Sonderegger et al., 2010a).

Although canonical Wnt signaling is strongly elevated upon EVT formation, CTBs also respond to Wnt signals. Wntdependent activation of TCF/ $\beta$-catenin provoked increased proliferation and expression of the cell cycle regulator cyclin D1 as well as induction of Wnt signaling components (Pollheimer et al., 2006). Although TCF-4 is absent from proliferative CTBs, the canonical pathway might be activated through TCF-3 which is present in both CTBs and EVTs (Figure 3).

Furthermore, epigenetic analyses provided evidence for a general activation of Wnt signaling in placental tissues and isolated trophoblasts. Genes encoding negative regulators of the pathway, i.e., APC, sFRP2 and engrailed-1 were shown to be hypermethylated in trophoblasts, whereas these changes were not observed in placental fibroblast or leukocytes (Novakovic et al., 2008; Wong et al., 2008). This suggests that specific activation of the pathway in trophoblasts could play a role in placentation. In addition, other effectors than Wnt ligands likely contribute to stabilization of $\beta$-catenin and TCF/ $\beta$-catenin-dependent trophoblast proliferation and invasion. Activation of protease activated receptor-1 (PAR1) provoked an increase in these processes whereas siRNAmediated gene silencing of PAR1 or addition of soluble inhibitors downregulated TCF/ $\beta$-catenin-induced proliferation and motility (Grisaru-Granovsky et al., 2009). Expression of StarD7, a member of the StAR1 lipid transfer proteins promoting proliferation and invasion of choriocarcinoma cells, was shown to be directly controlled by TCF/ $\beta$-catenin (Rena et al., 2009; Flores-Martin et al., 2012).

In summary, the present literature implicates canonical Wnt signaling in human trophoblast proliferation and invasion. 
However, the question of whether TCF molecules are indeed regulators of EVT formation, in other words control the switch from proliferation to cell cycle arrest and differentiation is still unknown and currently under investigation in our laboratory. So far, canonical Wnt signaling has been identified as a regulator of trophoblast cell fusion. GCM1, the most critical factor in syncytialisation controlling expression of the fusogenic proteins syncytin- 1 and -2 , harbors TCF binding sites in one of its introns and silencing of TCF- 4 or $\beta$-catenin impaired cAMPinduced cell fusion of BeWo choriocarcinoma cells (Matsuura et al., 2011). Moreover, Wnt targets such as Axin, BMP and activin membrane-bound inhibitor (BAMBI), and LEF-1 increased upon elevation of cAMP. However, it has to be mentioned that LEF-1 is only expressed in stromal cells of human placentae and TCF-3 and -4 are absent from villous CTBs after the 6th week of gestation (Pollheimer et al., 2006). Since trophoblast fusion occurs until the end of pregnancy, Wnt-dependent GCM1 expression and syncytialization may only operate during very early stages of human gestation. Similar to mice, Wnt signaling might also play a role in early human trophoblast lineage determination since the pathway was found to be activated upon BMP4mediated differentiation of embryonic stem cells into trophoblasts (Marchand et al., 2011).

\section{Wnt TARGET GENES AND THE ROLE OF Wnt-DEPENDENT TRANSCRIPTION FACTORS IN EPITHELIAL TO MESENCHYMAL TRANSITION}

Numerous studies indicated that cancer cell invasion shares several features with trophoblast invasion although the latter is precisely controlled in time and space. Besides expression of proteases, EVTs produce critical integrins such as the fibronectin receptor integrin $\alpha 5 \beta 1$ and the collagen/laminin receptor integrin $\alpha 1 \beta 1$ promoting trophoblast adhesion and migration (Damsky et al., 1994; Aplin et al., 1999). Conversely, EGF receptor 1 (EGFR1), indicative for the proliferative capacity of trophoblasts as well as integrin $\alpha 6$ (ITGA6), a marker of the polarized epithelium, were downregulated during EVT differentiation (Jokhi et al., 1994). Changes in the mRNA expression pattern of genes involved in EVT invasion and differentiation can also be monitored in our published chip data (Bilban et al., 2009) which are accessible via GEO profiles $^{2}$. ITGA6 and EGFR are highly expressed in the five different CTB cell pools but weakly present in the six EVT preparations confirming the published literature (Figure 3). In contrast, HLAG1, and the pro-migratory genes integrin $\alpha 1$ (ITGA1), integrin $\alpha 5$ (ITGA5) and fibronectin 1 (FN1) were upregulated in EVTs. Interestingly, various mRNAs such as BAMBI, a marker of metastasis in colon cancer (Fritzmann et al., 2009), insulin-like growth factor 2 (IGF2), inducible nitric oxide synthase (iNOS), fibronectin 1 (FN1), MMP-2, Notch2, uPAR, and Snail (also known as Snail1), which are all direct targets of $\mathrm{TCF} / \beta$-catenin ${ }^{1}$, were found to be increased in the EVT pools concomitant with the upregulation of TCF-4 (Figure 3). Indeed, these genes have already been implicated in the control of trophoblast motility (Bischof et al., 2000; Lala and Chakraborty, 2003; Harris et al., 2008; Hunkapiller et al., 2011). Therefore, we speculate that nuclear

${ }^{2}$ http://www.ncbi.nlm.nih.gov/geoprofiles/?term=GDS3523[ACCN] recruitment of $\beta$-catenin and increased expression of TCF- 4 in EVTs drives a set of genes promoting trophoblast invasion and migration.

Another molecular process critically involved in cancer cell invasion and metastasis is epithelial to mesenchymal transition (EMT), in which epithelial cells lose their polarity and gain fibroblast-like properties promoting invasion and migration (Zheng and Kang, 2013). Interestingly, EMT in cancer cells also provokes growth arrest and cells have to revert back to an epithelial phenotype (MET) allowing for cell growth and distant metastasis formation (Brabletz, 2012). Analyses of gene expression profiles suggest that EMT also occurs in invasive trophoblasts (Figure 3) which have stopped proliferation allowing for differentiation to take place. Although invasive trophoblasts do not induce mesenchymal vimentin, at least in vitro, and maintain expression of the epithelial marker cytokeratin 7 , they upregulate typical EMT-associated mRNAs such as heat shock protein 47 (HSP47), Snail, ITGA5, ITGAB1, fibroblast-specific protein 1 (FSP1), MMP2 , and secreted protein acidic and rich in cysteine (SPARC) and downregulate genes associated with cell-cell adhesion and epithelial polarity such as the tight junction proteins occludin (OCLN) and ZO1. Also, transient loss of adherens junction proteins, i.e., membrane-bound $\beta$-catenin and E-cadherin, has been detected in the proximal invasion zone of anchoring villi using immunofluorescence in first trimester placental tissues (Zhou et al., 1997b). Elevated Wnt signaling, expression of LEF/TCF and nuclear recruitment of $\beta$-catenin is also a typical feature of EMT (Moustakas and Heldin, 2007). Hence, similar to cancer cells, induction of TCF-4 upon invasive trophoblast differentiation could orchestrate an EMT-like program to promote cell motility. In this process, TCF- 4 could act as master regulator since it may not only directly control expression of pro-migratory EMT genes but also activate other critical key regulatory transcription factors inducing EMT such as Snail, Slug or ZEB1 (Medici et al., 2008; Sanchez-Tillo et al., 2011).

\section{Wnt signaling in gestational diseases}

Changes in gene expression as well as in epigenetic modifications of Wnt signaling components were shown to be associated with different gestational diseases. Compared to normal tissues, higher numbers of $\beta$-catenin-positive EVT nuclei were detected in placentae of complete hydatidiform mole (CHM) suggesting that aberrant Wnt signaling could contribute to abnormal invasion in this pregnancy disorder (Pollheimer et al., 2006). Genes encoding APC and sFRP2 were shown to be hypermethylated in choriocarcinoma cells, indicating that inactivation of negative regulators of Wnt signaling likely contributes to the formation and/or progression of trophoblastic cancer cells (Novakovic et al., 2008; Wong et al., 2008). Similarly, Dkk1 was found to be absent from choriocarcinoma cells and re-expression of the gene induced growth arrest and apoptosis suggesting that the loss of Dkk1 is critical for tumor cell proliferation (Peng et al., 2006). In contrast, Dkk1 and sFRP4 were increased whereas Wnt2 and $\beta$-catenin were decreased in tissues of preeclamptic patients (Zhang et al., 2013a,b). Therefore, downregulation of the pathway could contribute to failed placentation and shallow trophoblast invasion observed in these pregnancies. Along those lines, elevated 


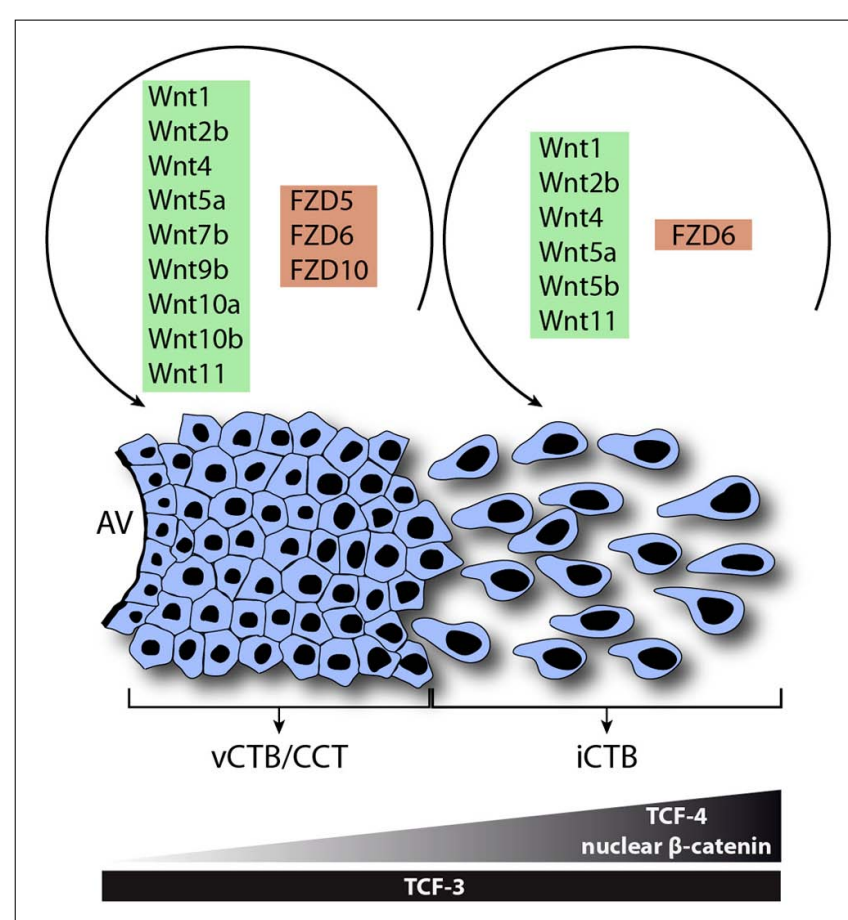

FIGURE 4 | Model system for the role of Wnt signaling in function and differentiation of the human anchoring villus. Wnt ligands and Fzd receptors expressed in vCTBs/CCTs and EVTs are shown. During EVT formation, Wnt7b, Wnt9b, Wnt10a, Wnt10b, Fzd5, and Fzd10 are downregulated suggesting a role in trophoblast proliferation. However, interstitial cytotrophoblasts (iCTBs) upregulate TCF-4 and nuclear $\beta$-catenin to promote trophoblast motility and possibly EVT differentiation.

levels of Dkk1 were detected in women with recurrent abortions (Bao et al., 2013). Interestingly, cytomegalovirus (CMV) infection, a putative cause of spontaneous abortion and preterm delivery, was shown to decrease trophoblast proliferation and invasion involving inhibition of Wnt signaling. Infection of trophoblastic SGHPL- 4 cells with the virus altered the localization of $\beta$-catenin and induced its degradation as well as downregulation of a canonical Wnt reporter (Angelova et al., 2012). Some of these effects might be exerted via peroxisome proliferator-activated receptor $\gamma$ (PPAR- $\gamma$ ) a negative regulator of trophoblast invasion, which is activated upon CMV infection and was shown to provoke proteasomal degradation of $\beta$-catenin in other cells (Liu et al., 2006; Rauwel et al., 2010).

\section{REFERENCES}

Al-Harthi, L. (2012). Wnt/beta-catenin and its diverse physiological cell signaling pathways in neurodegenerative and neuropsychiatric disorders. J. Neuroimmune Pharmacol. 7, 725-730. doi: 10.1007/s11481-0129412-x

Angelova, M., Zwezdaryk, K., Ferris, M., Shan, B., Morris, C. A., and Sullivan, D. E. (2012). Human cytomegalovirus infection dysregulates the canonical Wnt/beta-catenin signaling pathway.
PLoS Pathog. 8:e1002959. doi: 10.1371/journal.ppat.1002959

Anson-Cartwright, L., Dawson, K., Holmyard, D., Fisher, S. J., Lazzarini, R. A., and Cross, J. C. (2000). The glial cells missing- 1 protein is essential for branching morphogenesis in the chorioallantoic placenta. Nat. Genet. 25, 311-314. doi: 10.1038/ 77076

Aoki, M., Mieda, M., Ikeda, T., Hamada, Y., Nakamura, H., and Okamoto, H. (2007). R-spondin3 is required for mouse placental development.

\section{CONCLUSIONS}

In conclusion, the present literature suggests that Wnt signaling is critical for physiological processes of human trophoblasts. The pathway could play a role in blastocyst adhesion, implantation and early trophoblast lineage decisions. Moreover, Wnt signaling could regulate trophoblast cell fusion as well as development of the anchoring villus controlling proliferation, invasion and differentiation. In first trimester placenta numerous canonical and non-canonical Wnt ligands are expressed in CTBs and likely regulate proliferation or other functions of these cells through the most abundant receptors, i.e., Fzd5 and Fzd10 (Figure 4). Differentiation of CTBs into growth-arrested invasive EVTs is associated with increased expression of TCF-4, nuclear recruitment of $\beta$-catenin and elevated canonical Wnt activity controlling trophoblast motility potentially through Fzd6. Furthermore, TCF- $4 / \beta$-catenin could activate a set of genes promoting invasion as well as the EMT-like features of migratory trophoblasts. Hence, Wnt signaling likely contributes to the strong, intrinsic differentiation program of EVTs and their inherently invasive properties. Hyperactivation of autocrine Wnt signaling could play a role in trophoblast disorders with elevated proliferation and invasion such as CHM and choriocarcinomas whereas downregulation of the pathway could be a cause of impaired placentation and trophoblast invasion observed in preeclampsia. Epigenetic changes such as methylation of negative regulators of Wnt signaling could contribute to the induction of Wnt signaling likely promoting normal placentation as well as trophoblast tumor progression. Besides autocrine control decidual Wnt ligands could modulate trophoblast function via canonical and/or non-canonical pathways. The fact that Dkk1 is expressed in the decidua and increased upon progesterone treatment could suggest a mechanism to restrain the extent of trophoblast invasion. Further studies are needed to delineate specific Wnt-Fzd interactions in human trophoblasts and to define the role of non-canonical Wnt signaling in normal and aberrant trophoblast proliferation, invasion and differentiation.

\section{ACKNOWLEDGMENTS}

Research in the laboratory is supported by grants of the Austrian Science Fund (P-22687-B13 to Martin Knöfler and P-25187B13 to JJürgen Pollheimer) as well as by grant AP00574OFF of the Herzfelder'sche Familienstiftung and by grant 14147 of the Austrian National Bank donated to Martin Knöfler and Jürgen Pollheimer, respectively. We thank V. Fock for critical reading of the manuscript.

Dev. Biol. 301, 218-226. doi: 10.1016/j.ydbio.2006.08.018

Aplin, J. D. (2010). Developmental cell biology of human villous trophoblast: current research problems. Int. J. Dev. Biol. 54, 323-329. doi: 10.1387/ijdb.082759ja

Aplin, J. D., Haigh, T., Jones, C. J., Church, H. J., and Vicovac, L. (1999). Development of cytotrophoblast columns from explanted first-trimester human placental villi: role of fibronectin and integrin alpha5beta1. Biol. Reprod. 60,
828-838. doi: 10.1095/biolreprod60. 4.828

Aplin, J. D., Lacey, H., Haigh, T., Jones, C. J., Chen, C. P., and Westwood, M. (2000). Growth factor-extracellular matrix synergy in the control of trophoblast invasion. Biochem. Soc. Trans. 28, 199-202.

Apps, R., Murphy, S. P., Fernando, R., Gardner, L., Ahad, T., and Moffett, A. (2009). Human leucocyte antigen (HLA) expression of primary trophoblast cells and placental cell lines, determined using single 
antigen beads to characterize allotype specificities of anti-HLA antibodies. Immunology 127, 26-39. doi: 10.1111/j.1365-2567.2008.03019.x

Apps, R., Sharkey, A., Gardner, L., Male, V., Trotter, M., Miller, N., et al. (2011). Genome-wide expression profile of first trimester villous and extravillous human trophoblast cells. Placenta 32, 33-43. doi: 10.1016/j.placenta.2010.10.010

Arango, N. A., Szotek, P. P., Manganaro, T. F., Oliva, E., Donahoe, P. K., and Teixeira, J. (2005). Conditional deletion of beta-catenin in the mesenchyme of the developing mouse uterus results in a switch to adipogenesis in the myometrium. Dev. Biol. 288, 276-283. doi: 10.1016/j.ydbio.2005.09.045

Archbold, H. C., Yang, Y. X., Chen, L., and Cadigan, K. M. (2012). How do they do Wnt they do?: regulation of transcription by the Wnt/betacatenin pathway. Acta Physiol. (Oxf.) 204, 74-109. doi: 10.1111/j.17481716.2011.02293.x

Baczyk, D., Drewlo, S., Proctor, L., Dunk, C., Lye, S., and Kingdom, J. (2009). Glial cell missing-1 transcription factor is required for the differentiation of the human trophoblast. Cell Death Differ. 16, 719-727. doi: 10.1038/cdd.2009.1

Bansal, A. S., Bora, S. A., Saso, S., Smith, J. R., Johnson, M. R., and Thum, M. Y. (2012). Mechanism of human chorionic gonadotrophin-mediated immunomodulation in pregnancy. Expert Rev. Clin. Immunol. 8, 747753. doi: 10.1586/eci.12.77

Bao, S. H., Shuai, W., Tong, J., Wang, L., Chen, P., and Duan, T. (2013). Increased Dickkopf-1 expression in patients with unexplained recurrent spontaneous miscarriage. Clin. Exp. Immunol. 172, 437-443. doi: 10.1111/cei.12066

Beildeck, M. E., Gelmann, E. P., and Byers, S. W. (2010). Crossregulation of signaling pathways: an example of nuclear hormone receptors and the canonical Wnt pathway. Exp. Cell Res. 316, 1763-1772. doi: 10.1016/j.yexcr.2010.02.001

Biadasiewicz, K., Sonderegger, S., Haslinger, P., Haider, S., Saleh, L., Fiala, C., et al. (2011). Transcription factor AP-2alpha promotes EGFdependent invasion of human trophoblast. Endocrinology 152, 14581469. doi: 10.1210/en.2010-0936

Bilban, M., Haslinger, P., Prast, J., Klinglmuller, F., Woelfel, T., Haider, S., et al. (2009). Identification of novel trophoblast invasionrelated genes: heme oxygenase-1 controls motility via peroxisome proliferator-activated receptor gamma. Endocrinology 150, 10001013. doi: 10.1210/en.2008-0456

Bilban, M., Tauber, S., Haslinger, P., Pollheimer, J., Saleh, L., Pehamberger, H., et al. (2010). Trophoblast invasion: assessment of cellular models using gene expression signatures. Placenta 31, 989-996. doi: 10.1016/j.placenta.2010.08.011

Bilic, J., Huang, Y. L., Davidson, G., Zimmermann, T., Cruciat, C. M., Bienz, M., et al. (2007). Wnt induces LRP6 signalosomes and promotes dishevelled-dependent LRP6 phosphorylation. Science 316, 1619-1622. doi: 10.1126/science.1137065

Bischof, P., Meisser, A., and Campana, A. (2000). Paracrine and autocrine regulators of trophoblast invasion a review. Placenta 21(Suppl. A), S55S60. doi: 10.1053/plac.2000.0521

Brabletz, T. (2012). To differentiate or not - routes towards metastasis. Nat. Rev. Cancer 12, 425-436. doi: 10.1038/nrc3265

Bulmer, J. N., Williams, P. J., and Lash, G. E. (2010). Immune cells in the placental bed. Int. J. Dev. Biol. 54, 281-294. doi: 10.1387/ijdb.082763jb

Burton, G. J., Jauniaux, E., and Charnock-Jones, D. S. (2007). Human early placental development: potential roles of the endometrial glands. Placenta 28(Suppl. A), S64-S69. doi: 10.1016/j.placenta.2007.01.007

Burton, G. J., Jauniaux, E., and Charnock-Jones, D. S. (2010). The influence of the intrauterine environment on human placental development. Int. J. Dev. Biol. 54, 303-312. doi: $10.1387 / \mathrm{ijdb} .082764 \mathrm{gb}$

Camilli, T. C., and Weeraratna, A. T. (2010). Striking the target in Wnt$\mathrm{y}$ conditions: intervening in Wnt signaling during cancer progression. Biochem. Pharmacol. 80, 702-711. doi: 10.1016/j.bcp.2010.03.002

Caniggia, I., Grisaru-Gravnosky, S., Kuliszewsky, M., Post, M., and Lye, S. J. (1999). Inhibition of TGFbeta 3 restores the invasive capability of extravillous trophoblasts in preeclamptic pregnancies. J. Clin. Invest. 103, 1641-1650. doi: 10.1172/JCI6380

Caniggia, I., Mostachfi, H., Winter, J., Gassmann, M., Lye, S. J., Kuliszewski, M., et al. (2000a). Hypoxia-inducible factor-1 mediates the biological effects of oxygen on human trophoblast differentiation through TGFbeta(3). J. Clin. Invest. 105, 577-587. doi: 10.1172/JCI8316

Caniggia, I., Winter, J., Lye, S. J., and Post, M. (2000b). Oxygen and placental development during the first trimester: implications for the pathophysiology of pre-eclampsia. Placenta 21(Suppl. A), S25-S30. doi: 10.1053/plac.1999.0522

Chawengsaksophak, K., De Graaff, W., Rossant, J., Deschamps, J., and Beck, F. (2004). Cdx2 is essential for axial elongation in mouse development. Proc. Natl. Acad. Sci. U.S.A. 101, 7641-7645. doi: 10.1073/pnas.0401654101

Chen, Q., Zhang, Y., Lu, J., Wang, Q., Wang, S., Cao, Y., et al. (2009). Embryo-uterine cross-talk during implantation: the role of Wnt signaling. Mol. Hum. Reprod. 15, 215-221. doi: 10.1093/molehr/gap009

Clevers, H. (2006). Wnt/beta-catenin signaling in development and disease. Cell 127, 469-480. doi: 10.1016/j.cell.2006.10.018

Cross, J. C., Nakano, H., Natale, D. R., Simmons, D. G., and Watson, E. D. (2006). Branching morphogenesis during development of placental villi. Differentiation 74, 393-401. doi: 10.1111/j.1432-0436.2006.00103.x

Cross, J. C., Werb, Z., and Fisher, S. J. (1994). Implantation and the placenta: key pieces of the development puzzle. Science 266, 1508-1518. doi: 10.1126/science.7985020

Damsky, C. H., Librach, C., Lim, K. H., Fitzgerald, M. L., Mcmaster, M. T., Janatpour, M., et al. (1994). Integrin switching regulates normal trophoblast invasion. Development 120 , 3657-3666.

De, A. (2011). Wnt/Ca2+ signaling pathway: a brief overview. Acta Biochim. Biophys. Sin. (Shanghai) 43, 745-756. doi: 10.1093/abbs/gmr079

Denicol, A. C., Dobbs, K. B., Mclean, K. M., Carambula, S. F., Loureiro, B., and Hansen, P. J. (2013). Canonical WNT signaling regulates development of bovine embryos to the blastocyst stage. Sci. Rep. 3, 1266. doi: 10.1038/srep01266

De Vries, W. N., Evsikov, A. V., Haac, B. E., Fancher, K. S., Holbrook, A. E., Kemler, R., et al. (2004). Maternal beta-catenin and E-cadherin in mouse development. Development 131, 4435-4445. doi: 10.1242/dev.01316

Duncan, W. C., Shaw, J. L., Burgess, S., Mcdonald, S. E., Critchley, H. O., and Horne, A. W. (2011). Ectopic pregnancy as a model to identify endometrial genes and signaling pathways important in decidualization and regulated by local trophoblast. PLoS ONE 6:e23595. doi: 10.1371/journal.pone.0023595

Flores-Martin, J., Rena, V., Marquez, S., Panzetta-Dutari, G. M., and Genti-Raimondi, S. (2012). StarD7 knockdown modulates ABCG2 expression, cell migration, proliferation, and differentiation of human choriocarcinoma JEG-3 cells. PLOS ONE 7:e44152. doi: 10.1371/journal.pone.0044152

Forbes, K., Westwood, M., Baker, P. N., and Aplin, J. D. (2008). Insulin-like growth factor I and II regulate the life cycle of trophoblast in the developing human placenta. Am. J. Physiol. Cell Physiol. 294, C1313-C1322. doi: 10.1152/ajpcell.00035.2008

Fradkin, L. G., Dura, J. M., and Noordermeer, J. N. (2010). Ryks: new partners for Wnts in the developing and regenerating nervous system. Trends Neurosci. 33, 84-92. doi: 10.1016/j.tins.2009.11.005

Fritzmann, J., Morkel, M., Besser, D., Budczies, J., Kosel, F., Brembeck, F. H., et al. (2009). A colorectal cancer expression profile that includes transforming growth factor beta inhibitor BAMBI predicts metastatic potential. Gastroenterology 137, 165-175. doi: 10.1053/j.gastro.2009.03.041

Galceran, J., Farinas, I., Depew, M. J., Clevers, H., and Grosschedl, R. (1999). Wnt3a-/--like phenotype and limb deficiency in $\operatorname{Lef1}(-/-) \operatorname{Tcf} 1(-/-)$ mice. Genes Dev. 13, 709-717. doi: 10.1101/gad.13.6.709

Georgiades, P., Ferguson-Smith, A. C., and Burton, G. J. (2002). Comparative developmental anatomy of the murine and human definitive placentae. Placenta 23, 3-19. doi: 10.1053/plac.2001.0738

Golan, T., Yaniv, A., Bafico, A., Liu, G., and Gazit, A. (2004). The human Frizzled 6 (HFz6) acts as a negative regulator of the canonical Wnt. beta-catenin signaling cascade. J. Biol. Chem. 279, 14879-14888. doi: 10.1074/jbc.M306421200

Gordon, M. D., and Nusse, R. (2006). Wnt signaling: multiple pathways, multiple receptors, and multiple transcription factors. $J$. Biol. Chem. 281, 22429-22433. doi: 10.1074/jbc.R600015200

Grisaru-Granovsky, S., Maoz, M., Barzilay, O., Yin, Y. J., Prus, D., and BarShavit, R. (2009). Protease activated receptor-1, PAR1, promotes placenta trophoblast invasion and betacatenin stabilization. J. Cell. Physiol. 218, 512-521. doi: 10.1002/jcp.21625 Haegel, H., Larue, L., Ohsugi, M., Fedorov, L., Herrenknecht, K., and Kemler, R. (1995). Lack of betacatenin affects mouse development at gastrulation. Development 121 , 3529-3537.

Haider, S., and Knöfler, M. (2009). Human tumour necrosis factor: 
physiological and pathological roles in placenta and endometrium. Placenta 30, 111-123. doi: 10.1016/j.placenta.2008.10.012

Hamilton, W. J., and Boyd, J. D. (1960). Development of the human placenta in the first three months of gestation. J. Anat. 94, 297-328.

Harris, L. K. (2011). IFPA gabor than award lecture: transformation of the spiral arteries in human pregnancy: key events in the remodelling timeline. Placenta 32(Suppl. 2), S154-S158. doi: 10.1016/j.placenta.2010.11.018

Harris, L. K., Mccormick, J., Cartwright, J. E., Whitley, G. S., and Dash, P. R. (2008). S-nitrosylation of proteins at the leading edge of migrating trophoblasts by inducible nitric oxide synthase promotes trophoblast invasion. Exp. Cell Res. 314, 1765-1776. doi: 10.1016/j.yexcr.2008.02.010

Harwood, B. N., Cross, S. K., Radford, E. E., Haac, B. E., and De Vries, W. N. (2008). Members of the WNT signaling pathways are widely expressed in mouse ovaries, oocytes, and cleavage stage embryos. Dev. Dyn. 237, 1099-1111. doi: 10.1002/dvdy.21491

Hayashi, K., Erikson, D. W., Tilford, S. A., Bany, B. M., Maclean, J. A. II, Rucker, E. B. III, et al. (2009). Wnt genes in the mouse uterus: potential regulation of implantation. Biol. Reprod. 80, 989-1000. doi: 10.1095/biolreprod.108.075416

He, S., Pant, D., Schiffmacher, A., Meece, A., and Keefer, C. L. (2008). Lymphoid enhancer factor 1-mediated Wnt signaling promotes the initiation of trophoblast lineage differentiation in mouse embryonic stem cells. Stem Cells 26, 842-849. doi: 10.1634/stemcells.2007-0356

Hendrickx, M., and Leyns, L. (2008). Non-conventional Frizzled ligands and Wnt receptors. Dev. Growth Differ. 50, 229-243. doi: 10.1111/j.1440169X.2008.01016.X

Herr, P., Hausmann, G., and Basler, K. (2012). WNT secretion and signalling in human disease. Trends Mol. Med. 18, 483-493. doi: 10.1016/j.molmed.2012.06.008

Hess, A. P., Hamilton, A. E., Talbi, S., Dosiou, C., Nyegaard, M., Nayak, N., et al. (2007). Decidual stromal cell response to paracrine signals from the trophoblast: amplification of immune and angiogenic modulators. Biol. Reprod. 76, 102-117. doi: 10.1095/biolreprod.106.054791

Hiby, S. E., Walker, J. J., O'Shaughnessy K, M., Redman, C. W., Carrington, M., Trowsdale, J., et al. (2004). Combinations of maternal KIR and fetal HLA-C genes influence the risk of preeclampsia and reproductive success. J. Exp. Med. 200, 957-965. doi: 10.1084/jem.20041214

Hunkapiller, N. M., Gasperowicz, M., Kapidzic, M., Plaks, V., Maltepe, E., Kitajewski, J., etal. (2011). A role for Notch signaling in trophoblast endovascular invasion and in the pathogenesis of pre-eclampsia. Development 138, 2987-2998. doi: 10.1242/dev.066589

Hustin, J., Jauniaux, E., and Schaaps, J. P. (1990). Histological study of the materno-embryonic interface in spontaneous abortion. Placenta 11, 477-486. doi: 10.1016/S01434004(05)80193-6

Ishikawa, T., Tamai, Y., Zorn, A. M., Yoshida, H., Seldin, M. F., Nishikawa, S., et al. (2001). Mouse Wnt receptor gene Fzd5 is essential for yolk sac and placental angiogenesis. Development $128,25-33$.

Ishitani, T., and Ishitani, S. (2013). Nemo-like kinase, a multifaceted cell signaling regulator. Cell. Signal. 25, 190-197. doi: 10.1016/j.cellsig.2012.09.017

Ishitani, T., Ninomiya-Tsuji, J., Nagai, S., Nishita, M., Meneghini, M., Barker, N., etal. (1999). The TAK1-NLK-MAPK-related pathway antagonizes signalling between betacatenin and transcription factor TCF. Nature 399, 798-802. doi: $10.1038 / 21674$

Janatpour, M. J., Mcmaster, M. T., Genbacev, O., Zhou, Y., Dong, J., Cross, J. C., et al. (2000). Id-2 regulates critical aspects of human cytotrophoblast differentiation, invasion and migration. Development 127, 549-558.

Jokhi, P. P., King, A., and Loke, Y. W. (1994). Reciprocal expression of epidermal growth factor receptor (EGF$\mathrm{R}$ ) and c-erbB2 by non-invasive and invasive human trophoblast populations. Cytokine 6, 433-442. doi: 10.1016/1043-4666(94)90068-X

Kim, S. E., Lee, W. J., and Choi, K. Y. (2007). The PI3 kinase-Akt pathway mediates Wnt3a-induced proliferation. Cell. Signal. 19, 511-518. doi: 10.1016/j.cellsig.2006.08.008

Knöfler, M. (2010). Critical growth factors and signalling pathways controlling human trophoblast invasion. Int. J. Dev. Biol. 54, 269-280. doi: 10.1387/ijdb.082769mk

Knöfler, M., and Pollheimer, J. (2012). IFPA Award in Placentology lecture: molecular regulation of human trophoblast invasion. Placenta 33(Suppl.), S55-S62. doi: 10.1016/j.placenta.2011.09.019

Kohn, A. D., and Moon, R. T. (2005). Wnt and calcium signaling: beta-catenin-independent pathways.
Cell Calcium 38, 439-446. doi: 10.1016/j.ceca.2005.06.022

Komiya, Y., and Habas, R. (2008). Wnt signal transduction pathways. Organogenesis 4, 68-75. doi: 10.4161/org.4.2.5851

Lala, P. K., and Chakraborty, C. (2003). Factors regulating trophoblast migration and invasiveness: possible derangements contributing to preeclampsia and fetal injury. Placenta 24, 575-587. doi: 10.1016/S01434004(03)00063-8

Lala, P. K., and Graham, C. H. (1990). Mechanisms of trophoblast invasiveness and their control: the role of proteases and protease inhibitors. Cancer Metastasis Rev. 9, 369-379. doi: 10.1007/BF00049525

Li, Q., Kannan, A., Das, A., Demayo, F J., Hornsby, P. J., Young, S. L., et al. (2013). WNT4 acts downstream of BMP2 and functions via beta-catenin signaling pathway to regulate human endometrial stromal cell differentiation. Endocrinology 154, 446-457. doi: 10.1210/en.2012-1585

Lim, K. H., Zhou, Y., Janatpour, M., Mcmaster, M., Bass, K., Chun, S. H., et al. (1997). Human cytotrophoblast differentiation/invasion is abnormal in pre-eclampsia. Am. J. Pathol. 151, 1809-1818.

Liu, J., Wang, H., Zuo, Y., and Farmer, S. R. (2006). Functional interaction between peroxisome proliferatoractivated receptor gamma and betacatenin. Mol. Cell. Biol. 26, 58275837. doi: 10.1128/MCB.00441-06

Liu, Y., Kodithuwakku, S. P., Ng, P. Y., Chai, J., Ng, E. H., Yeung, W. S., et al. (2010). Excessive ovarian stimulation up-regulates the Wntsignaling molecule DKK1 in human endometrium and may affect implantation: an in vitro co-culture study. Hum. Reprod. 25, 479-490. doi: 10.1093/humrep/dep429

Logan, C. Y., and Nusse, R. (2004). The Wnt signaling pathway in development and disease. Annu. Rev. Cell Dev. Biol. 20, 781-810. doi: 10.1146/ annurev.cellbio.20.010403.113126

Loregger, T., Pollheimer, J., and Knöfler, M. (2003). Regulatory transcription factors controlling function and differentiation of human trophoblast-a review. Placenta 24(Suppl. A), S104S110. doi: 10.1053/plac.2002.0929

Lu, J., Zhang, S., Nakano, H., Simmons, D. G., Wang, S., Kong, S., et al. (2013). A positive feedback loop involving Gcm1 and Fzd5 directs chorionic branching morphogenesis in the placenta. PLoS Biol. 11:e1001536. doi: 10.1371/journal.pbio.1001536

Ma, L., and Wang, H. Y. (2006). Suppression of cyclic GMP-dependent protein kinase is essential to the Wnt/cGMP/Ca2+ pathway. J. Biol. Chem. 281, 30990-31001. doi: 10.1074/jbc.M603603200

Mao, J., Wang, J., Liu, B., Pan, W., Farr, G. H. III, Flynn, C., et al. (2001). Lowdensity lipoprotein receptor-related protein-5 binds to Axin and regulates the canonical Wnt signaling pathway. Mol. Cell 7, 801-809. doi: 10.1016/S1097-2765(01)00224-6

Marchand, M., Horcajadas, J. A., Esteban, F. J., Mcelroy, S. L., Fisher, S. J., and Giudice, L. C. (2011). Transcriptomic signature of trophoblast differentiation in a human embryonic stem cell model. Biol. Reprod. 84, 1258-1271. doi: 10.1095/biolreprod.110.086413

Matsuura, K., Jigami, T., Taniue, K., Morishita, Y., Adachi, S., Senda, T., et al. (2011). Identification of a link between Wnt/beta-catenin signalling and the cell fusion pathway. Nat. Commun. 2, 548. doi: 10.1038/ncomms 1551

Medici, D., Hay, E. D., and Olsen, B. R. (2008). Snail and Slug promote epithelial-mesenchymal transition through beta-catenin-T-cell factor-4-dependent expression of transforming growth factor-beta3. Mol. Biol. Cell 19, 4875-4887. doi: 10.1091/mbc.E08-05-0506

Mericskay, M., Kitajewski, J., and Sassoon, D. (2004). Wnt5a is required for proper epithelial-mesenchymal interactions in the uterus. Development 131, 2061-2072. doi: 10.1242/dev.01090

Metcalfe, C., and Bienz, M. (2011). Inhibition of GSK3 by Wnt signalling - two contrasting models. J. Cell Sci. 124, 3537-3544. doi: $10.1242 /$ jcs. 091991

Mikels, A. J., and Nusse, R. (2006). Purified Wnt5a protein activates or inhibits beta-catenin-TCF signaling depending on receptor context. PLoS Biol. 4:e115. doi: 10.1371/journal.pbio.0040115

Miller, C., and Sassoon, D. A. (1998). Wnt-7a maintains appropriate uterine patterning during the development of the mouse female reproductive tract. Development 125 , 3201-3211.

Minami, Y., Oishi, I., Endo, M., and Nishita, M. (2010). Ror-family receptor tyrosine kinases in noncanonical Wnt signaling: their implications in developmental morphogenesis and human diseases. Dev. Dyn. 239, 1-15.

Mohamed, O. A., Dufort, D., and Clarke, H. J. (2004). Expression and estradiol regulation of Wnt genes in the mouse blastocyst identify 
a candidate pathway for embryomaternal signaling at implantation. Biol. Reprod. 71, 417-424. doi: 10.1095/biolreprod.103.025692

Mohamed, O. A., Jonnaert, M., LabelleDumais, C., Kuroda, K., Clarke, H. J., and Dufort, D. (2005). Uterine $\mathrm{Wnt} /$ beta-catenin signaling is required for implantation. Proc. Natl. Acad. Sci. U.S.A. 102, 8579-8584. doi: 10.1073/pnas.0500612102

Monkley, S. J., Delaney, S. J., Pennisi, D. J., Christiansen, J. H., and Wainwright, B. J. (1996). Targeted disruption of the Wnt2 gene results in placentation defects. Development 122, 3343-3353.

Morrish, D. W., Dakour, J., and Li, H. (1998). Functional regulation of human trophoblast differentiation. J. Reprod. Immunol. 39, 179-195. doi: 10.1016/S0165-0378(98)00021-7

Moustakas, A., and Heldin, C. H. (2007). Signaling networks guiding epithelial-mesenchymal transitions during embryogenesis and cancer progression. Cancer Sci. 98, 15121520. doi: 10.1111/j.1349-7006.2007. 00550.x

Nadeem, L., Munir, S., Fu, G., Dunk, C., Baczyk, D., Caniggia, I., et al. (2011). Nodal signals through activin receptor-like kinase 7 to inhibit trophoblast migration and invasion: implication in the pathogenesis of preeclampsia. Am. J. Pathol. 178, 1177-1189. doi: 10.1016/j.ajpath.2010.11.066

Naito, A. T., Akazawa, H., Takano, H., Minamino, T., Nagai, T., Aburatani, H., et al. (2005). Phosphatidylinositol 3-kinase-Akt pathway plays a critical role in early cardiomyogenesis by regulating canonical Wnt signaling. Circ. Res. 97, 144-151. doi: 10.1161/01.RES.0000175241.92285.f8

Nishita, M., Enomoto, M., Yamagata, K., and Minami, Y. (2010). Cell/tissue-tropic functions of Wnt5a signaling in normal and cancer cells. Trends Cell Biol. 20, 346-354. doi: 10.1016/j.tcb.2010.03.001

Novakovic, B., Rakyan, V., Ng, H. K., Manuelpillai, U., Dewi, C., Wong, N. C., etal. (2008). Specific tumour-associated methylation in normal human term placenta and first-trimester cytotrophoblasts. Mol. Hum. Reprod. 14, 547-554. doi: 10.1093/molehr/gan046

Nusse, R., Brown, A., Papkoff, J., Scambler, P., Shackleford, G., Mcmahon, A., etal. (1991). A new nomenclature for int- 1 and related genes: the Wnt gene family. Cell 64, 231. doi: 10.1016/0092-8674(91)90633-A

Oreshkova, T., Dimitrov, R., and Mourdjeva, M. (2012). A cross-talk of decidual stromal cells, trophoblast, and immune cells: a prerequisite for the success of pregnancy. Am. J. Reprod. Immunol. 68, 366-373. doi: 10.1111/j.1600-0897.2012.01165.x

Parr, B. A., Cornish, V. A., Cybulsky, M. I., and Mcmahon, A. P. (2001). Wnt7b regulates placental development in mice. Dev. Biol. 237, 324332. doi: 10.1006/dbio.2001.0373

Peng, S., Li, J., Miao, C., Jia, L., Hu, Z., Zhao, P., et al. (2008). Dickkopf-1 secreted by decidual cells promotes trophoblast cell invasion during murine placentation. Reproduction 135, 367-375. doi: 10.1530/REP-070191

Peng, S., Miao, C., Li, J., Fan, X., Cao, Y., and Duan, E. (2006). Dickkopf-1 induced apoptosis in human placental choriocarcinoma is independent of canonical Wnt signaling. Biochem. Biophys. Res. Commun. 350, 641-647. doi: 10.1016/j.bbrc.2006.09.087

Pijnenborg, R., Anthony, J., Davey, D. A., Rees, A., Tiltman, A., Vercruysse, L., etal. (1991). Placental bed spiral arteries in the hypertensive disorders of pregnancy. $\mathrm{Br}$. J. Obstet. Gynaecol. 98, 648-655. doi: 10.1111/j.1471-0528.1991.tb13450.x

Pijnenborg, R., Vercruysse, L., and Hanssens, M. (2006). The uterine spiral arteries in human pregnancy: facts and controversies. Placenta 27, 939-958. doi: 10.1016/j.placenta.2005.12.006

Poehlmann, T. G., Fitzgerald, J. S., Meissner, A., Wengenmayer, T., Schleussner, E., Friedrich, K., et al. (2005). Trophoblast invasion: tuning through LIF, signalling via Stat3. Placenta 26(Suppl. A), S37-S41. doi: 10.1016/j.placenta.2005.01.007

Polakis, P. (2000). Wnt signaling and cancer. Genes Dev. 14, 1837-1851.

Pollheimer, J., Bauer, S., Huber, A., Husslein, P., Aplin, J. D., and Knöfler, M. (2004). Expression pattern of collagen XVIII and its cleavage product, the angiogenesis inhibitor endostatin, at the fetal-maternal interface. Placenta 25, 770-779. doi: 10.1016/j. placenta.2004.03.003

Pollheimer, J., Haslinger, P., Fock, V., Prast, J., Saleh, L., Biadasiewicz, K., etal. (2011). Endostatin suppresses IGF-II-mediated signaling and invasion of human extravillous trophoblasts. Endocrinology 152, 4431-4442. doi: 10.1210/en.20111196

Pollheimer, J., Husslein, P., and Knöfler, M. (2005). Invasive trophoblasts generate regulatory collagen XVIII cleavage products. Placenta 26(Suppl. A), S42-S45. doi: 10.1016/j.placenta.2004.12.005
Pollheimer, J., and Knöfler, M. (2005). Signalling pathways regulating the invasive differentiation of human trophoblasts: a review. Placenta 26(Suppl. A), S21-S30. doi: 10.1016/j.placenta.2004.11.013

Pollheimer, J., Loregger, T., Sonderegger, S., Saleh, L., Bauer, S., Bilban, M., et al. (2006). Activation of the canonical wingless/T-cell factor signaling pathway promotes invasive differentiation of human trophoblast. Am. J. Pathol. 168, 1134-1147. doi: 10.2353/ajpath.2006.050686

Prakobphol, A., Genbacev, O., Gormley, M., Kapidzic, M., and Fisher, S. J. (2006). A role for the Lselectin adhesion system in mediating cytotrophoblast emigration from the placenta. Dev. Biol. 298, 107-117. doi: 10.1016/j.ydbio.2006.06.020

Rauwel, B., Mariame, B., Martin, H., Nielsen, R., Allart, S. Pipy, B., etal. (2010). Activation of peroxisome proliferatoractivated receptor gamma by human cytomegalovirus for de novo replication impairs migration and invasiveness of cytotrophoblasts from early placentas. J. Virol. 84, 2946-2954. doi: 10.1128/JVI.01779-09

Red-Horse, K., Zhou, Y., Genbacev, O., Prakobphol, A., Foulk, R., Mcmaster, M., etal. (2004). Trophoblast differentiation during embryo implantation and formation of the maternal-fetal interface. J. Clin. Invest. 114, 744-754.

Redman, C. W., and Sargent, I. L. (2010). Immunology of preeclampsia. Am. J. Reprod. Immunol. 63, 534-543. doi: 10.1111/j.16000897.2010.00831.x

Redman, C. W., Tannetta, D. S., Dragovic, R. A., Gardiner, C., Southcombe, J. H., Collett, G. P., et al. (2012). Review: does size matter? Placental debris and the pathophysiology of pre-eclampsia. Placenta 33(Suppl.), S48-S54. doi: 10.1016/j.placenta.2011.12.006

Rena, V., Angeletti, S., Panzetta-Dutari, G., and Genti-Raimondi, S. (2009). Activation of beta-catenin signalling increases StarD7 gene expression in JEG-3 cells. Placenta 30, 876-883. doi: 10.1016/j.placenta.2009.07.010

Robson, A., Harris, L. K., Innes, B. A., Lash, G. E., Aljunaidy, M. M., Aplin, J. D., etal. (2012). Uterine natural killer cells initiate spiral artery remodeling in human pregnancy. FASEB J. 26, 4876-4885. doi: 10.1096/fj.12-210310

Roose, J., and Clevers, H. (1999). TCF transcription factors: molecular switches in carcinogenesis. Biochim. Biophys. Acta 1424, M23-M37.
Sanchez-Tillo, E., De Barrios, O., Siles, L., Cuatrecasas, M., Castells, A., and Postigo, A. (2011). beta-catenin/ TCF 4 complex induces the epithelialto-mesenchymal transition (EMT)activator ZEB1 to regulate tumor invasiveness. Proc. Natl. Acad. Sci. U.S.A. 108, 19204-19209. doi: 10.1073/pnas.1108977108

Saneyoshi, T., Kume, S., Amasaki, Y., and Mikoshiba, K. (2002). The Wnt/calcium pathway activates NFAT and promotes ventral cell fate in Xenopus embryos. Nature 417, 295-299. doi: 10.1038/417295a

Sonderegger, S., Haslinger, P., Sabri, A., Leisser, C., Otten, J. V., Fiala, C., et al. (2010a). Wingless (Wnt)-3A induces trophoblast migration and matrix metalloproteinase- 2 secretion through canonical Wnt signaling and protein kinase B/AKT activation. Endocrinology 151, 211-220. doi: 10.1210/en.2009-0557

Sonderegger, S., Husslein, H., Leisser, C., and Knöfler, M. (2007). Complex expression pattern of Wnt ligands and frizzled receptors in human placenta and its trophoblast subtypes. Placenta 28(Suppl. A), S97-S102. doi: 10.1016/j.placenta. 2006.11.003

Sonderegger, S., Pollheimer, J., and Knöfler, M. (2010b). Wnt signalling in implantation, decidualisation and placental differentiation review. Placenta 31, 839-847. doi: 10.1016/j.placenta.2010.07.011

Stamos, J. L., and Weis, W. I. (2013). The beta-catenin destruction complex. Cold Spring Harb. Perspect. Biol. 5, a007898. doi: 10.1101/cshperspect.a007898

Tal, R. (2012). The role of hypoxia and hypoxia-inducible factor-1alpha in preeclampsia pathogenesis. Biol. Reprod. 87, 134. doi: 10.1095/biolreprod.112.102723

Tsang, H., Cheung, T. Y., Kodithuwakku, S. P., Chai, J., Yeung, W. S., Wong, C. K., et al. (2012). 2,3,7,8-Tetrachlorodibenzo-p-dioxin (TCDD) suppresses spheroids attachment on endometrial epithelial cells through the down-regulation of the Wnt-signaling pathway. Reprod. Toxicol. 33, 60-66. doi: 10.1016/j.reprotox.2011.11.002

Tulac, S., Nayak, N. R., Kao, L. C., Van Waes, M., Huang, J., Lobo, S., et al. (2003). Identification, characterization, and regulation of the canonical Wnt signaling pathway in human endometrium. J. Clin. Endocrinol. Metab. 88, 3860-3866. doi: 10.1210/jc.2003-030494

Tulac, S., Overgaard, M. T., Hamilton, A. E., Jumbe, N. L., Suchanek, E., 
and Giudice, L. C. (2006). Dickkopf1 , an inhibitor of Wnt signaling, is regulated by progesterone in human endometrial stromal cells. J. Clin. Endocrinol. Metab. 91, 1453-1461. doi: 10.1210/jc.2005-0769

Vainio, S., Heikkila, M., Kispert, A., Chin, N., and Mcmahon, A. P. (1999). Female development in mammals is regulated by Wnt-4 signalling. Nature 397, 405-409. doi: 10.1038/17068

van Amerongen, R., and Nusse, R. (2009). Towards an integrated view of Wnt signaling in development. Development 136, 3205-3214. doi: 10.1242/dev.033910

van der Horst, P. H., Wang, Y., Van Der Zee, M., Burger, C. W., and Blok, L. J. (2012). Interaction between sex hormones and WNT/beta-catenin signal transduction in endometrial physiology and disease. Mol. Cell. Endocrinol. 358, 176-184. doi: 10.1016/j.mce.2011.06.010

van Dijk, M., and Oudejans, C. B. (2011). STOX1: key player in trophoblast dysfunction underlying early onset preeclampsia with growth retardation. J. Pregnancy 2011, 521826. doi: 10.1155/2011/521826

Wang, Q., Lu, J., Zhang, S., Wang, S., Wang, W., Wang, B., et al. (2013). Wnt6 is essential for stromal cell proliferation during decidualization in mice. Biol. Reprod. 88, 5. doi: 10.1095/biolreprod.112.104687

Wang, Y. (2009). Wnt/planar cell polarity signaling: a new paradigm for cancer therapy. Mol. Cancer Ther. 8, 2103-2109. doi: 10.1158/15357163.MCT-09-0282
Wetendorf, M., and DeMayo, F. J. (2012). The progesterone receptor regulates implantation, decidualization, and glandular development via a complex paracrine signaling network. Mol. Cell. Endocrinol.357, 108 118. doi: 10.1016/j.mce.2011.10.028

Wodarz, A., and Nusse, R. (1998). Mechanisms of Wnt signaling in development. Annu. Rev. Cell Dev. Biol. 14, 59-88. doi: 10.1146/annurev.cellbio.14.1.59

Wong, N. C., Novakovic, B., Weinrich, B., Dewi, C., Andronikos, R., Sibson, M., et al. (2008). Methylation of the adenomatous polyposis coli (APC) gene in human placenta and hypermethylation in choriocarcinoma cells. Cancer Lett. 268, 56-62. doi: 10.1016/j.canlet.2008.03. 033

Wu, B., Crampton, S. P., and Hughes, C. C. (2007). Wnt signaling induces matrix metalloproteinase expression and regulates $\mathrm{T}$ cell transmigration. Immunity 26, 227-239. doi: 10.1016/j.immuni.2006.12.007

Wu, Q. L., Zierold, C., and Ranheim, E. A. (2009). Dysregulation of Frizzled 6 is a critical component of B-cell leukemogenesis in a mouse model of chronic lymphocytic leukemia. Blood 113, 3031-3039. doi: 10.1182/blood2008-06-163303

Xie, H., Tranguch, S., Jia, X., Zhang, H., Das, S. K., Dey, S. K., et al. (2008). Inactivation of nuclear Wntbeta-catenin signaling limits blastocyst competency for implantation. Development 135, 717-727. doi: 10.1242/dev.015339
Yun, M. S., Kim, S. E., Jeon, S. H., Lee, J. S., and Choi, K. Y. (2005). Both ERK and Wnt/beta-catenin pathways are involved in Wnt3a-induced proliferation. J. Cell Sci. 118, 313-322. doi: $10.1242 /$ jcs.01601

Zhang, Z., Li, H., Zhang, L., Jia L., and Wang, P. (2013a). Differential expression of beta-catenin and dickkopf-1 in the third trimester placentas from normal and preeclamptic pregnancies: a comparative study. Reprod. Biol. Endocrinol. 11, 17. doi: 10.1186/1477-7827-11-17

Zhang, Z., Zhang, L., Jia, L., Wang, P., and Gao, Y. (2013b). Association of Wnt2 and sFRP4 expression in the third trimester placenta in women with severe preeclampsia. Reprod. Sci. 20, 981-989. doi: 10.1177/1933719112472740

Zheng, H., and Kang, Y. (2013). Multilayer control of the EMT master regulators. Oncogene. doi: 10.1038/onc.2013.128 [Epub ahead of print].

Zhou, Y., Damsky, C. H., and Fisher, S. J. (1997a). Preeclampsia is associated with failure of human cytotrophoblasts to mimic a vascular adhesion phenotype. One cause of defective endovascular invasion in this syndrome? J. Clin. Invest. 99, 2152-2164. doi: 10.1172/JCI11 9388

Zhou, Y., Fisher, S. J., Janatpour, M. Genbacev, O., Dejana, E., Wheelock, M., et al. (1997b). Human cytotrophoblasts adopt a vascular phenotype as they differentiate. A strategy for successful endovascular invasion? J.
Clin. Invest. 99, 2139-2151. doi: 10.1172/JCI119387

Zhou, Y., Gormley, M. J., Hunkapiller, N. M., Kapidzic, M., Stolyarov, Y., Feng, V., et al. (2013). Reversal of gene dysregulation in cultured cytotrophoblasts reveals possible causes of preeclampsia. J. Clin Invest. 123, 2862-2872. doi: 10.1172/ JCI66966

Conflict of Interest Statement: The authors declare that the research was conducted in the absence of any commercial or financial relationships that could be construed as a potential conflict of interest.

Received: 26 June 2013; accepted: 06 September 2013; published online: 26 September 2013.

Citation: Knöfler $M$ and Pollheimer J (2013) Human placental trophoblast invasion and differentiation: a particular focus on Wnt signaling. Front. Genet. 4:190. doi: 10.3389/fgene.2013.00190

This article was submitted to Epigenomics and Epigenetics, a section of the journal Frontiers in Genetics.

Copyright (c) 2013 Knöfler and Pollheimer. This is an open-access article distributed under the terms of the Creative Commons Attribution License (CC BY). The use, distribution or reproduction in other forums is permitted, provided the original author(s) or licensor are credited and that the original publication in this journal is cited, in accordance with accepted academic practice. No use, distribution or reproduction is permitted which does not comply with these terms. 